\title{
Autophosphorylated CaMKII Facilitates Spike Propagation in Rat Optic Nerve
}

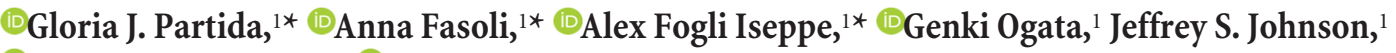 \\ 마thya Thambiaiyah, ${ }^{1}$ Christopher L. Passaglia, ${ }^{2}$ and Andrew T. Ishida ${ }^{1,3}$ \\ ${ }^{1}$ Department of Neurobiology, Physiology and Behavior, University of California, Davis, California 95616, ${ }^{2}$ Department of Chemical and Biomedical \\ Engineering, University of South Florida, Tampa, Florida 33612, and ${ }^{3}$ Department of Ophthalmology and Vision Science, University of California, \\ Sacramento, California 95817
}

Repeated spike firing can transmit information at synapses and modulate spike timing, shape, and conduction velocity. These latter effects have been found to result from voltage-induced changes in ion currents and could alter the signals carried by axons. Here, we test whether $\mathrm{Ca}^{2+} /$ calmodulin-dependent protein kinase II (CaMKII) regulates spike propagation in adult rat optic nerve. We find that small-, medium-, and large-diameter axons bind anti-Thr286-phosphorylated CaMKII (pT286) antibodies and that, in isolated optic nerves, electrical stimulation reduces pT286 levels, spike propagation is hastened by CaMKII autophosphorylation and slowed by CaMKII dephosphorylation, single and multiple spikes slow propagation of subsequently activated spikes, and more frequent stimulation produces greater slowing. Likewise, exposing freely moving animals to flickering illumination reduces pT286 levels in optic nerves and electrically eliciting spikes in vivo in either the optic nerve or optic chiasm slows subsequent spike propagation in the optic nerve. By increasing the time that elapses between successive spikes as they propagate, pT286 dephosphorylation and activity-induced spike slowing reduce the frequency of propagated spikes below the frequency at which they were elicited and would thus limit the frequency at which axons synaptically drive target neurons. Consistent with this, the ability of retinal ganglion cells to drive at least some lateral geniculate neurons has been found to increase when presented with light flashes at low and moderate temporal frequencies but less so at high frequencies. Activity-induced decreases in spike frequency may also reduce the energy required to maintain normal intracellular $\mathrm{Na}^{+}$and $\mathrm{Ca}^{2+}$ levels.

Key words: CaMKII; conduction velocity; interspike interval; optic nerve; retino-geniculate synapse

Significance Statement

By propagating along axons at constant velocities, spikes could drive synapses as frequently as they are initiated. However, the onset of spiking has been found to alter the conduction velocity of subsequent ("follower") spikes in various preparations. Here, we find that spikes reduce spike frequency in rat optic nerve by slowing follower spike propagation and that electrically stimulated spiking ex vivo and spike-generating flickering illumination in vivo produce net decreases in axonal $\mathrm{Ca}^{2+} / \mathrm{calmodulin}$-dependent protein kinase II (CaMKII) autophosphorylation. Consistent with these effects, propagation speed increases and decreases, respectively, with CaMKII autophosphorylation and dephosphorylation. Lowering spike frequency by CaMKII dephosphorylation is a novel consequence of axonal spiking and light adaptation that could decrease synaptic gain as stimulus frequency increases and may also reduce energy use.

\section{Introduction}

Axons generate, conduct, and, under some conditions, also modulate spikes. At low and moderate stimulus frequencies, spikes

The work was supported by the National Eye Institute-National Institutes of Health (Grant EY008120 to A.T.I., Grant EY027037 to C.L.P., and Grant P30 EY012576 to J.S. Werner). The authors thank W.M. Usrey and T.G. Weyand for discussions and comments on the manuscript; B.C. Mulloney for discussions, advice on spike recording, and use typically propagate without changes in amplitude, firing probability, and velocity. By contrast, higher frequencies can modulate

of equipment; B.N. Cohen and A.V. Gomes for discussions; and T.W. Stradleigh for participation at the beginning of this study.

The authors declare no competing financial interests.

${ }^{*}$ G.J.P., A.F., and A.F.I. contributed equally to this work.

Correspondence should be addressed to Andrew T. Ishida, Department of Neurobiology, Physiology and Behav-

ior, University of California, One Shields Avenue, Davis, CA 95616-8519. E-mail: atishida@ucdavis.edu.

DOI:10.1523/JNEUROSCI.0078-18.2018

Copyright $\odot 2018$ the authors $\quad 0270-6474 / 18 / 388087-19 \$ 15.00 / 0$ 
spike amplitude, duration, propagation speed, and/or firing probability (Swadlow et al., 1980; Debanne et al., 1997; Williams and Stuart, 1999; Geiger and Jonas, 2000; Raastad and Shepherd, 2003; Khaliq and Raman, 2005; Meeks et al., 2005; Monsivais et al., 2005). At synapses that transmit information efficaciously if more than one spike arrives at the synaptic terminal within a narrow range of interspike intervals (Singer et al., 1972; Mastronarde, 1987; Stevens and Wang, 1995; Usrey et al., 1998; Sincich et al., 2007; Weyand, 2007), axons that maintain steady firing probabilities and conduction velocities would be particularly useful because they preserve the time (i.e., interspike interval) that elapses between spikes while they propagate. On the other hand, if the firing of one spike altered the conduction velocity of a subsequently elicited spike, then interspike intervals would increase or decrease as the spikes propagate, depending on whether the first (cardinal) spike travels more quickly or slowly than the next (follower) spike. This, in turn, could modulate information transfer at synapses that require particular interspike intervals to transmit signals to postsynaptic cells.

What cellular mechanisms control interspike intervals in axons? For three reasons, we begin to address this question by recording from optic nerve. First, some studies have found that single cardinal spikes alter the conduction velocity of subsequently elicited spikes in retinal ganglion cell (RGC) axons (Bishop et al., 1953; Foster et al., 1982), whereas other studies have reported that this does not occur (George et al., 1984). Second, voltage-gated $\mathrm{Ca}^{2+}$ channels, $\mathrm{Ca}^{2+} /$ calmodulin-dependent protein kinase II (CaMKII), and changes in intracellular $\mathrm{Ca}^{2+}$ concentration have been detected in RGC axons (Brown et al., 2001; Calkins et al., 2005; Weitz et al., 2013) and these alter spike propagation in other preparations (Hodgkin and Keynes, 1956; Lüscher et al., 1996; Tsubokawa et al., 2000). Third, previous studies have shown that illumination activates CaMKII in RGC somata (Ogata et al., 2012) and that electrical stimulation elevates $\mathrm{Ca}^{2+}$ concentration in optic nerve axons (Lev-Ram and Grinvald, 1987; Verbny et al., 2002). However, these studies did not identify conditions that activate CaMKII in optic nerve and did not show that changes in CaMKII activation alter spike propagation.

Here, we test whether cardinal spikes alter the propagation speed of follower spikes, whether illumination and electrical stimulation activate CaMKII, and whether changes in CaMKII autophosphorylation alter spike propagation, all in adult rat optic nerve. We find that single cardinal spikes slow the propagation of follower spikes; that repetitive spiking reduces the level of autophosphorylated CaMKII (pT286) and slows follower spike propagation further; that an inhibitor of CaMKII activation slows cardinal and follower spike propagation; that a protein phosphatase inhibitor increases pT286 levels and accelerates cardinal and follower spike propagation; that optic nerve axons bind antibodies against pT286 and protein phosphatase 2A; and that pT286 levels are reduced by spiking elicited in vivo by flickering illumination. In addition, we electrically stimulate adult rat optic chiasm and optic nerve in vivo and find that spiking slows propagation of subsequent spikes in the optic nerve. By increasing interspike intervals between cardinal and follower spikes, activity-induced spike slowing would tend to limit signal transmission, as observed at retinogeniculate synapses during responses to light flashes at high temporal frequencies. By reducing $\mathrm{Na}^{+}$and $\mathrm{Ca}^{2+}$ influx, interspike interval increases could also reduce the energy used by RGCs to maintain normal intracellular $\mathrm{Na}^{+}$and $\mathrm{Ca}^{2+}$ levels.

\section{Materials and Methods}

Animals. Adult rats were used for this study based on the presence and autophosphorylation of CaMKII in their RGC somata (Bronstein et al., 1988; Terashima et al., 1994; Ogata et al., 2012) and the presence of CaMKII in their optic nerves (Lund and McQuarrie, 2001). Long-Evans rats [male and female; postnatal day 60 (P60)-P120; 150-250 g] were obtained from a commercial supplier (Envigo Bioproducts) and housed in standard cages at $\sim 23^{\circ} \mathrm{C}$ on a $12 \mathrm{~h} / 12 \mathrm{~h}$ light/dark cycle. For the optic nerve experiments reported here, each rat was anesthetized by intraperitoneal ketamine and xylazine $(70-100$ and $5-10 \mathrm{mg} / \mathrm{kg}$, respectively; see below for the source of chemicals used in this study) and decapitated. Each optic nerve was isolated by dissecting it from the back of each eye and from the optic chiasm and passing it through the optic foramen. These nerves were Western blotted, immunohistochemically stained, or electrophysiologically tested, as described below. For the retina experiments reported here, each rat was anesthetized as described above, enucleated, and killed by a lethal dose of Fatal Plus ( $150 \mathrm{mg} / \mathrm{kg}$, intraperitoneal). After hemisecting the eyes, the retinae were dissected away from the posterior eyecups and electrophysiologically tested as described below. All animal care and experimental protocols were approved by the Animal Use and Care Administrative Advisory Committee of the University of California-Davis. The in vivo optic nerve spikes were recorded by modification of a protocol described in detail previously (Tang et al., 2016). Briefly, adult Brown-Norway rats (male, 300-400 g; Harlan Laboratories) were anesthetized by intraperitoneal injection of ketamine hydrochloride $(75 \mathrm{mg} / \mathrm{kg})$ and xylazine $(7.5 \mathrm{mg} / \mathrm{kg})$, supplemented as needed. Animals were rested on a heating pad $\left(37^{\circ} \mathrm{C}\right)$ and maintained under anesthesia for the remainder of the experiment via an intravenous infusion of ketamine $(30 \mathrm{mg} / \mathrm{kg} \cdot \mathrm{h})$, xylazine $(1.5 \mathrm{mg} / \mathrm{kg} \cdot \mathrm{h})$, and $0.9 \%$ physiological saline. A tracheotomy was performed to provide mechanical ventilation if necessary. Body temperature and heart rate were monitored with a rectal thermometer and ECG electrodes, respectively, and data were collected while vital signs remained at normal levels. Animals were killed with Euthasol $(50 \mathrm{mg} / \mathrm{kg})$ at the end of experiments. All procedures were approved by the Institutional Animal Care and Use Committee of the University of South Florida in accordance with National Institutes of Health guidelines.

Protein isolation. For Western blotting, optic nerves were placed in a capped microcentrifuge tube, frozen by dropping into liquid nitrogen, and homogenized in solubilization buffer $(320 \mathrm{mM}$ sucrose, $50 \mathrm{mM}$ $\mathrm{MgCl}_{2}, 7 \mathrm{M}$ urea, $10 \mathrm{mM}$ dithiothreitol, $100 \mathrm{mM}$ Tris- $\mathrm{HCl}, \mathrm{pH}$ 7.4). The homogenates were centrifuged at $600 \times g$ for $10 \mathrm{~min}$ at $4^{\circ} \mathrm{C}$. The resulting pellets were discarded and the supernatant was concentrated in centrifugal filters ( $30 \mathrm{kDa}$, Amicon). The concentrated homogenate was diluted in $200 \mu$ l of homogenization buffer $\left(320 \mathrm{mM}\right.$ sucrose, $50 \mathrm{mM} \mathrm{MgCl}_{2}, 100$ $\mathrm{mM}$ Tris- $\mathrm{HCl}, \mathrm{pH}$ 7.4), concentrated again, and then diluted in a final volume of $65 \mu \mathrm{l}$ of homogenization buffer. The total protein concentration was determined using a bicinchoninic acid protein assay kit. All solutions were ice-cold and supplemented with protease and phosphatase inhibitor tablets.

Western blot. Aliquots of optic nerve homogenates were loaded into $4-12 \%$ gradient gel lanes (Bis-Tris; Invitrogen), electrophoretically separated in MOPS running buffer at $200 \mathrm{~V}$ for $1 \mathrm{~h}$, and transferred to polyvinyl difluoride (PVDF) membranes (Bio-Rad) at $30 \mathrm{~V}$ for $1 \mathrm{~h}$. Protein standards (SeeBlue Plus2) were run in lanes adjacent to the samples. Each PVDF membrane was immersed for $1 \mathrm{~h}$ in a protein-supplemented buffer solution (Superblock) and then incubated with primary antibodies on a rocker overnight at $4^{\circ} \mathrm{C}$. As a loading control, lanes were also immunostained for $\beta$-actin, myelin basic protein, or CaMKII. The membranes were then rinsed with TBS (supplemented with $0.5 \%$ Tween 20 ) and incubated in species-specific secondary antibody conjugated to fluorophores for $1 \mathrm{~h}$ at room temperature. The fluorescence of these fluorophores was visualized and imaged in a digital imager (FluorChem Q; Alpha Innotech). The fluorescence intensities of the immunostained protein bands were measured with software of the imager (AlphaView Q, ProteinSimple) and normalized to that of the loading control protein.

Fixation and immunohistochemistry. For immunostaining, optic nerves were immersed overnight at $4^{\circ} \mathrm{C}$ in a fixative containing formal- 
dehyde (4\% w/v) in PBS, pH 7.4, rinsed, embedded in 5\% (w/v) low-melt agarose at $37^{\circ} \mathrm{C}$, allowed to set for at least $60 \mathrm{~min}$ at $4^{\circ} \mathrm{C}$, and cut into blocks with a razor blade. These blocks were sectioned transversely or longitudinally at a thickness of $75-100 \mu \mathrm{m}$ on a vibrating microtome (VT1000S; Leica Microsystems). Free-floating sections were blocked and permeabilized for $24 \mathrm{~h}$ at $4^{\circ} \mathrm{C}$ in TBST (TBS plus $0.3 \% \mathrm{v} / \mathrm{v}$ Triton X-100, $\mathrm{pH}$ 7.4) supplemented with $5 \%$ normal donkey serum. The sections were incubated in primary antibody (either overnight at $37^{\circ} \mathrm{C}$ or for as long as $5 \mathrm{~d}$ at $4^{\circ} \mathrm{C}$ ), rinsed with PBS, incubated in secondary antibody (overnight at either $37^{\circ} \mathrm{C}$ or $4^{\circ} \mathrm{C}$ ), rinsed with PBS, and mounted in Prolong Diamond Antifade Mountant between glass coverslips (no. 1.5) and glass slides. Primary and secondary antibodies were diluted in TBST.

Antibody characterization. The mouse monoclonal anti-neurofilament antibody (BioLegend, clone SMI-312, RRID:AB_2566782) was generated against pan axonal neurofilaments, validated on Western blots by the manufacturer, and used at a dilution of $0.5 \mu \mathrm{g} / \mathrm{ml}$.

The rat monoclonal anti-myelin basic protein (MBP) IgG2a antibody (Abcam, clone 12, RRID:AB_305869) was generated against full-length cow MBP, binds to a region defined by aa $82-87$, and used at a dilution of 1:500. Antibody specificity was tested by the manufacturer using a synthetic peptide consisting of aa 82-99.

The mouse monoclonal anti-protein phosphatase $1 \alpha(\mathrm{PP} 1 \alpha)$ IgG1 antibody (Thermo Fisher Scientific, clone 10C6-3, RRID:AB_2533541) was generated against a mixture of two peptides from the C-terminal regions of human PP1 $\alpha$ protein and diluted to $2 \mu \mathrm{g} / \mathrm{ml}$. The manufacturer demonstrated antibody specificity by siRNA-mediated knockdown of the target protein.

The rabbit polyclonal anti-protein phosphatase $2 \mathrm{~A} \alpha$ catalytic subunit (PP2A $\alpha$ C subunit) IgG antibody (Thermo Fisher Scientific, RRID: AB_10983779) was generated against a synthetic peptide corresponding to amino acids at the C-terminus of human PP2A catalytic subunits and used at a dilution of 1:200. The manufacturer verified specificity by Western blot and immunohistochemistry.

The rabbit monoclonal anti-phospho-CaMKII IgG antibody (Cell Signaling Technology, clone D21E4, RRID:AB_2713889) was generated against a synthetic phosphopeptide corresponding to residues surrounding Thr287 of human CaMKII- $\beta$ protein and diluted to $1.85 \mu \mathrm{g} / \mathrm{ml}$. The rabbit polyclonal anti-phospho-CaMKII IgG antibody (Abcam, RRID: AB_305050) was generated against a synthetic phosphopeptide derived from a region of human CaM Kinase II- $\alpha$ that contains threonine 286 and diluted to $1.5 \mu \mathrm{g} / \mathrm{ml}$. The immunizing peptide (Cell Signaling Technology, catalog \#1712S) was used to control against nonspecific binding by both primary antibodies.

The mouse monoclonal anti-CaMKII $\alpha$ IgG $_{2 \mathrm{a}}$ antibody (Santa Cruz Biotechnology, clone A-1, RRID:AB_626789) was generated against a synthetic peptide corresponding to residues 303-478 of mouse CaMKII $\alpha$ protein and diluted to 1:200. The manufacturer ran positive controls on rat brain extracts.

The goat polyclonal anti- $\beta$-actin antibody (Abcam, RRID:AB_306374) was generated against a synthetic peptide within human $\beta$ actin amino acids 1-100 conjugated to keyhole limpet hemocyanin and diluted to $1: 400$. The manufacturer ran positive controls on Western-blotted HeLa, NIH3T3, PC12, and CHOK1 whole-cell lysates.

Signals attributed to the primary antibodies were visualized with donkey, species-specific, fluorophore-conjugated secondary antibodies (Jackson ImmunoResearch Laboratories, RRID:AB_2340684, RRID: AB_2492289, RRID:AB_2307351, RRID:AB_2340863) diluted typically to 1:500. The fluorophores were Alexa Fluor 488, Cy3, or Alexa Fluor 647.

Confocal imaging and image handling. Confocal images were acquired on a Leica TCS SP8 STED $3 \times$ high-sensitivity confocal microscope coupled with Leica Application Suite X software. The results reported here were collected by use of excitation lines for AF488 (499 nm), Cy3 (554 $\mathrm{nm}$ ), and AF647 $(653 \mathrm{~nm})$, an oil-immersion $100 \times$ objective (numerical aperture $=1.4$ ), optical sections at step sizes of $0.180 \mu \mathrm{m}$, and 5 -frame Kalman averaging for each optical section. For most imaging sessions, some sections were processed without primary antibody (i.e., stained with secondary antibody alone) and the laser intensity, pinhole diameter, and photomultiplier gain were selected so that the secondary antibody fluorescence intensity was indistinguishable from background fluorescence.

Datasets were imported into the ImageJ package Fiji (http://imagej. net/Fiji, RRID:SCR_002285). Changes in color space, adjustments to brightness or contrast (if any), and image overlays were made in Photoshop CS6 (Adobe Systems, RRID:SCR_014199).

Ex vivo optic nerve stimulation and recording. To test whether and how spiking alters spike propagation in rat optic nerve, we measured spikes elicited by depolarizing current pulses and repeated these measurements before, during, and after conditions that increase or decrease CaMKII autophosphorylation. Because effects of the reagents that we used typically develop over the course of several minutes and no study we know of has recorded intra-axonally from optic nerve axons for more than a few minutes (Eng et al., 1990), we used glass suction electrodes and carbon fiber electrodes to record continuously for hours while superfusing various media. In these recordings, each stimulation elicits a compound action potential (CAP) that typically displays two or three positive peaks (Sefton and Swinburn, 1964; Stys et al., 1991). The different peaks sum spikes propagating along axons of different diameters (Bishop et al., 1953) and these arise from different populations of RGCs (Boycott and Wässle, 1974). Ranked by the "time-to-peak" between the stimulus artifact and the maximum amplitude of each peak, these peaks will be denoted hereafter as $\mathrm{P} 1, \mathrm{P} 2$, and (if present) $\mathrm{P} 3$. The ratios of the timeto-peak of $\mathrm{P} 2$ to $\mathrm{P} 1$ and of $\mathrm{P} 3$ to $\mathrm{P} 1$ in our recordings agree with those reported for rat optic nerve responses to optic tract stimulation (Sefton and Swinburn, 1964).

For electrophysiological stimulation and recording, optic nerves were transferred to a Plexiglas recording chamber and connected to electrodes, with one end of each nerve gently drawn into a stimulating glass suction electrode (Stys et al., 1991) and the other end either drawn into a recording glass suction electrode or impaled with a recording carbon fiber electrode (Carbostar-1; Kation Scientific). Before commencing data collection, all optic nerves were equilibrated to Ames medium by continuous superfusion for $1 \mathrm{~h}$ (Stys et al., 1991). Spikes were then elicited while superfusing the nerves with control Ames medium and "test" (reagentcontaining) media. All solutions were bubbled with carbogen, warmed by a substage heater to $30-32^{\circ} \mathrm{C}$ (Stys et al., 1992b) and flowed through the recording chamber at $\sim 2 \mathrm{ml} / \mathrm{min}$.

The stimulus pulses were delivered from an optically isolated stimulator (STG 4002; Multi Channel Systems) that was controlled by a PC computer program (MC_Stimulus II, version 3.0.1; Multi Channel Systems, RRID:SCR_014955). The stimuli consisted of 100- $\mu$ s biphasic pulses of $\pm 1-16 \mathrm{~V}$ (50:50 duty cycle, negative first). To test the effect of single spikes on subsequent spikes, we used interstimulus intervals (ISIs) that exceeded the duration of CAPs that we recorded (i.e., $\geq 3 \mathrm{~ms}$ ). To test the effect of multiple spikes on subsequent spikes, we varied the number of "conditioning" pulses that preceded the "test" pulse. CAPs were amplified by a high impedance differential amplifier (npb EXT02B; npi Electronic), recorded at a bandwidth of $100 \mathrm{~Hz}$ to $3 \mathrm{kHz}$, and sampled at $100 \mathrm{kHz}$ using another PC program (pCLAMP, version 9.2.1.9; Molecular Devices, RRID:SCR_011323).

In vivo optic nerve stimulation and recording. To record spikes in vivo, a craniotomy was performed over the optic chiasm with the head supported in a stereotaxic apparatus. Brain tissue was removed and a bipolar needle electrode was lowered into the optic nerve at the base of the chiasm. The optic nerve was then transected behind the globe, the eye was discarded, and the glass tip of a suction electrode was positioned near the optic nerve stump. The nerve stump was gently aspirated into the suction electrode, which was filled with artificial CSF containing the following (in $\mathrm{mM}): 126 \mathrm{NaCl}, 3 \mathrm{KCl}, 2 \mathrm{CaCl}_{2}, 2 \mathrm{MgCl}_{2}, 1.2 \mathrm{NaH}_{2} \mathrm{PO}_{4}, 26 \mathrm{NaHCO}_{3}$, and 10 glucose, $\mathrm{pH}$ 7.45. A silver chloride wire coiled around the suction electrode tip served as the reference electrode. The pair of bipolar electrode leads was connected to an electrical stimulator (S48; Grass Instruments) and the pair of suction electrode leads was connected to an amplifier (Xcell-3x4; FHC). Spikes were activated antidromically by applying current pulses $(0.1 \mathrm{~ms})$ to the optic chiasm until a CAP was recorded in the optic nerve. In one preparation, spikes were also activated orthodromically by switching the connections of the leads (to stimulate the optic nerve and record at the optic chiasm). Evoked signals were 
amplified differentially $(10,000 \times)$, filtered ( $10 \mathrm{~Hz}$ to $1 \mathrm{kHz}$ ), digitally sampled at $100 \mathrm{kHz}$, stored on a hard drive, and processed offline.

These in vivo CAPs consisted of a larger peak and, in most cases $(n=2$ of 3 preparations recorded from), a smaller peak on the falling phase of the large peak. Based on the order of appearance after the stimulus artifact (i.e., as in our ex vivo recordings), we termed the large peak $\mathrm{P} 1$ and the shoulder-like peak P2. The CAP elicited by each stimulus was found to be fitted by sums of two four-parameter Gaussian functions. Therefore, the time-to-peak values were measured from the beginning of the stimulus artifact to the maximum amplitude of the entire response (i.e., the unfitted peak) and to the maximum amplitude of the Gaussian functions. Each function was of the following form:

$$
\mathrm{y}=a+b e^{-\left[(x-c)^{2} / 2 d^{2}\right]}
$$

where $a$ is a $y$-offset, $b$ is the height at the peak of the Gaussian, $c$ is time-to-peak, and $d$ is a sharpness factor. Using the "fmincon" function of MatLab, the following constraints were incorporated in these fits: $a$ ranged between -5 and $+5 \mu \mathrm{V}, b$ of $\mathrm{P} 1$ ranged from $20 \mu \mathrm{V}$ to the maximum amplitude of the recording, $b$ of $\mathrm{P} 2$ ranged from $5 \mu \mathrm{V}$ to the maximum amplitude of the recording, $c$ of $\mathrm{P} 1$ preceded the timing of the large peak, $c$ of $\mathrm{P} 2$ followed the timing of the large peak, $d$ ranged between 3 and 50 for P1, and $d$ ranged between 3 and 75 for P2.

Multielectrode array stimulation and recording. In some experiments, axonal spikes were activated and recorded on multielectrode arrays (60MEA200/30iR-ITO; Multi Channel Systems) from the vitreal side of whole, isolated retinae. These spikes were recorded in nine retinae from a total of 13 pairs of stimulating and recording electrodes that were separated by a few hundred micrometers (cf. Sekirnjak et al., 2006). The stimuli were biphasic current pulses and the analog data were acquired at a sampling frequency of $25 \mathrm{kHz}$ and stored on a hard disc. The time-topeak values were measured from digital averages of the spikes elicited by $\sim 100$ repetitions of the stimuli per pair of stimulating and recording electrodes.

Effects of changing CaMKII autophosphorylation. Effects of reagents and experimental conditions that increase or decrease CaMKII autophosphorylation were tested by Western blotting optic nerves that were incubated in either control Ames medium or "test" (reagent-containing) medium; by recording spikes that were elicited while superfusing the optic nerves with control medium, test medium, and control medium again; or by recording spikes before, during, and after eliciting spikes. In the early stages of this study, to screen reagent effectiveness, to compare optic nerves over identical periods of time ex vivo, and to minimize any possible effect of day-to-day differences in dissection, single optic nerves were transversely sliced into two segments (each $4-6 \mathrm{~mm}$ in length) and the segments were incubated in test solution or in control solution. In a few pilot experiments that used okadaic acid, the optic nerve segments were incubated in fixed volumes of medium and these incubations were performed at room temperature $\left(23^{\circ} \mathrm{C}\right)$ to minimize evaporation. Effects found were confirmed in subsequent experiments at $30-32^{\circ} \mathrm{C}$.

Dark and light adaptation. Rats were dark and light adapted as described in detail previously (Ogata et al., 2012). Briefly stated, rats were placed in light-tight boxes at 7:00 P.M. At 1:00 P.M. of the following day, one of the boxes was kept dark, while the interior of the other box was illuminated by two arrays of $505 \mathrm{~nm}$ LEDs (Optek Technology) attached to the box ceiling. The light exposures were $250-\mathrm{ms}$ flashes presented at $2 \mathrm{~Hz}$ over a period ranging from $30 \mathrm{~s}$ to $60 \mathrm{~min}$. Each rat was then killed as described above and, under dim red light $\left(<1 \mu \mathrm{W} / \mathrm{cm}^{2}\right.$ provided by a $650 \mathrm{~nm}$ LED), enucleated. The optic nerves were dissected under room light and processed by Western blotting.

Reagents. Reagents were obtained from the following sources: Abcam Biochemicals: tetrodotoxin; Bio-Rad: Tween 20; Calbiochem: dimethylsulfoxide, okadaic acid; Fisher Scientific: dimethylsulfoxide, PBS $\left(\mathrm{Ca}^{2+}\right.$ and $\mathrm{Mg}^{2+}$-free, $\mathrm{pH}$ 7.4), TBS (pH 7.4), urea; Jackson ImmunoResearch: normal donkey serum; Life Technologies: ProLong Diamond Antifade Mountant; Roche: cOmplete Mini, PhosSTOP; Sigma-Aldrich: ASB-14, dithiothreitol, ethanol, formaldehyde, $\mathrm{MgCl}_{2}$, sucrose; Thermo Fisher Scientific: bicinchoninic acid protein assay kit, low-melting-point agarose, MOPS running buffer, Restore PLUS Western blot Stripping Buf- fer, SeeBlue Plus2 Pre-Stained Protein Standard, SuperBlock, Triton X-100; United States Biological: Ames medium, $\mathrm{Ca}^{2+}$ - and $\mathrm{Mg}^{2+}$-free Ames medium; Virbac: Euthasol; Vortech: Fatal Plus; and Western Medical Supply: ketamine, xylazine.

Experimental design and statistical analysis. Standard electrophysiological methods were used to measure the time-to-peak of elicited CAPs and spikes ex vivo. Each reported value is the time elapsing between the beginning of the stimulus capacitive current and the maximum amplitude of the axonal response analyzed using pCLAMP. We used optic nerves that were typically $\sim 8 \mathrm{~mm}$ long and stimuli that elicited 2 or 3 peaks in the CAPs. Also, the data for a given condition were measured with only one type of recording electrode (glass or carbon fiber). However, some nerves fit better than others in the suction electrodes (cf. Stys et al., 1991). Moreover, we positioned the stimulating and recording electrodes where we obtained stable recordings even if this resulted in different interelectrode distances. As might therefore be expected, time-to-peak values differed from nerve to nerve. To minimize contributions of length differences to effects we tested for, we calculated changes for each optic nerve separately as a percentage increase or decrease relative to the control value and report the mean \pm SEM of the differences. For sufficiently large sample sizes, we used paired $t$ tests to assess whether differences were statistically significant and report the mean, SEM, and value range, sample size, and $p$-value. For datasets consisting of relatively small sample sizes, we used signed-rank tests to assess whether differences were statistically significant and formed box plots to illustrate the median, mean, and range of the raw data.

During analysis of the in vivo recordings, individual CAPs were considered "unfittable" and deleted if the $p$-value of the correlation coefficient of the fit with the data was not significant at 0.01 or if the $p$-value of the coefficient of determination was $>1 \mathrm{e}^{-4}$. Fewer than $0.2 \%$ of the CAPs that we recorded in vivo were discarded for these reasons. Also, the CAPs in one preparation lacked a discernible P2 peak. Because the sum of two or more Gaussian functions did not yield adequate fits, analysis for this preparation was limited to locating the raw peak.

Western blotting was used to detect proteins of interest in optic nerves collected under various experimental conditions. Because this entailed tissue homogenization, optic nerve samples were processed in pairs, with one maintained under the test condition and the other under a control condition. The pairs were either cut from a single optic nerve, were the left and right optic nerves of a single animal, or were the optic nerves of animals kept under different lighting conditions and collected on the same day. The value reported for single optic nerve samples is the fluorescence intensity measured by a digital imager normalized to that of a loading control protein (see above). The difference between each pair of nerves is expressed as the ratio of the test value to the control value (100*experimental/control). The difference for each condition is the mean of the differences for the pairs used in each experiment. To test whether spiking alters CaMKII autophosphorylation levels, Western blots were formed from optic nerves that were snap frozen immediately after stimulation by pulse protocols that slow spike propagation (e.g., a single epoch of 16 conditioning pulses). In other cases, the stimuli were pairs of pulses delivered for a total of 10-120 s. The first and second pulse of each pair was separated by $1,2,3$, or $5 \mathrm{~ms}$ (Fig. $1 A$ ). These intervals were presented in a randomized sequence and each pair of pulses was separated from the next pair by $1 \mathrm{~s}$. Because the net effects of these protocols on pT286 were indistinguishable, the results were pooled.

Immunostaining experiments were performed on at least three optic nerves per reported observation. Axon diameter and myelin thickness were measured in an average of 300 axons in a total of 11 optic nerves. These measurements were made from transverse and longitudinal sections that included axons of various diameters. The axon diameters were assessed in longitudinal sections to sample the diameter of axon segments that were more than a few micrometers long. The inner and outer diameters of myelin were assessed in transverse sections to sample round, perpendicularly sliced myelin profiles.

All observations reported here are based on measurements made in one or both optic nerves or retinae of at least three animals. Statistical analyses of the data were performed using Excel 2013 (Microsoft), MatLab R2014A (The MathWorks, RRID:SCR_001622), and R version 

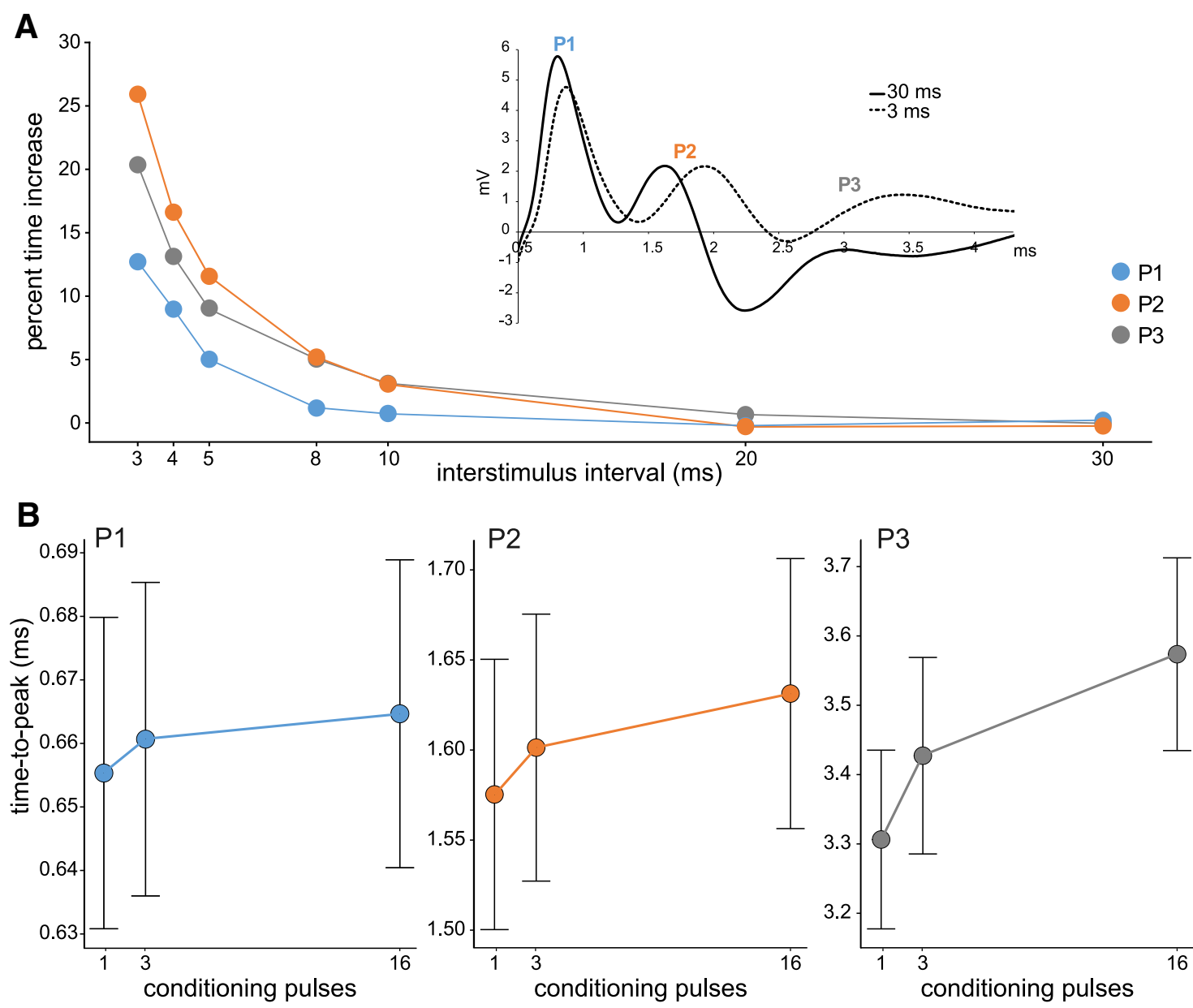

Figure 1. Slowing of optic nerve spike propagation by prior spiking. $A$, Inset, CAPs recorded with a glass suction electrode from an isolated rat optic nerve. CAPs were elicited by pairs of stimulus pulses; these stimuli were repeated 3 times for each ISI. The solid and dotted lines show the average of the "follower" CAPs (i.e., those elicited by the second pulse of each pulse pair) when the ISI was $30 \mathrm{~ms}$ (solid line) or $3 \mathrm{~ms}$ (dotted line). The peaks of the CAP are labeled P1, P2, and P3. A, Time-to-peak of P1, P2, and P3 at different ISI values. For each optic nerve, the time-to-peak of P1, P2, and P3 in the cardinal and follower CAPs were measured, normalized by the cardinal values, and multiplied by 100 . Each dot plots the difference between the mean of the percentage cardinal and follower values for the optic nerves recorded from ( $n=15, n=15$, and $n=11 \mathrm{for} P 1, \mathrm{P} 2$, and P3, respectively). Note the lack of spike slowing at 30 ms and the monotonic increase in slowing as the ISI decreases. $\boldsymbol{B}$, Increase in the time-to-peak of P1, P2, and P3 as the number of conditioning pulses increases. The data for P1, P2, and P3 are plotted in $\boldsymbol{A}$ and $\boldsymbol{B}$ by blue, orange, and gray dots, respectively. Dots and error bars plot the mean and SEM of the measured values.

3.4.1 (R Foundation for Statistical Computing, RRID:SCR_001905). Measurements presented without statistical analyses are given as mean \pm SEM and sample size.

\section{Results}

This study used extracellular stimulation and recording, Western blotting, and immunohistochemistry to test, in adult rat optic nerve, whether: (1) spiking alters the speed at which subsequent spikes propagate, (2) autophosphorylated CaMKII and associated protein phosphatases are present, (3) flickering illumination and repeated depolarizations alter CaMKII autophosphorylation levels, and (4) CaMKII autophosphorylation and dephosphorylation alter spike propagation.

\section{Spike-induced slowing of spike propagation}

Illumination elicits as many as a few hundred spikes per second $(\mathrm{Hz})$ in rat RGCs in situ (Brown and Rojas, 1965; Heine and Passaglia, 2011). To test whether repetitive spiking alters conduction velocity in RGC axons, we electrically stimulated excised optic nerves with pairs of current pulses separated by intervals ranging between 3 and $30 \mathrm{~ms}$. In response to a pair of pulses separated by $20 \mathrm{~ms}$ or more, the time-to-peak values of the dif- ferent peaks (P1, P2, and P3) of the CAP elicited by the second pulse did not significantly differ from those elicited by the first pulse (Fig. 1A). Therefore, in response to a pair of pulses at an instantaneous stimulus frequency of $50 \mathrm{~Hz}$ or less, single cardinal CAPs did not alter the time-to-peak of single follower CAPs. By contrast, the time-to-peak of P1, P2, and P3 elicited by the second pulse increased monotonically as the stimulus intervals decreased from 20 to $3 \mathrm{~ms}$ (Fig. 1A, Table 1). The time-to-peak increases of $\mathrm{P} 1, \mathrm{P} 2$, and $\mathrm{P} 3$ all reached $\sim 50 \%$ of the increases at $3 \mathrm{~ms}$ at stimulus intervals of $\sim 5 \mathrm{~ms}$ and the difference between the timeto-peak values at 3 and $20 \mathrm{~ms}$ were statistically significant (paired $t$ test $)$ for $\mathrm{P} 1(0.08 \pm 0.01 \mathrm{~ms}, n=15$, range $0.04-0.15 \mathrm{~ms}$, $p$-value $\left.=5 \times 10^{-7}\right), \mathrm{P} 2(0.37 \pm 0.03 \mathrm{~ms}, n=15$, range $0.20-$ $0.65 \mathrm{~ms}, p$-value $\left.=1 \times 10^{-8}\right)$, and P3 $(0.60 \pm 0.07 \mathrm{~ms}, n=11$, range $0.23-1.01 \mathrm{~ms}, p$-value $\left.=1 \times 10^{-5}\right)$.

Because Figure $1 A$ and Table 1 show that the time-to-peak of a follower spike is not increased if a cardinal spike precedes it by $20 \mathrm{~ms}$, one might not expect conditioning spikes at 20-ms intervals to alter the time-to-peak of test spikes that follow them. We tested this by eliciting a pair of CAPs at a 5-ms interval preceded by a variable number of CAPs at 20 -ms intervals and found that 
Table 1. Change in time-to-peak at different ISIs

\begin{tabular}{lcll}
\hline Peakno. & ISI (ms) & $\begin{array}{l}\text { C-F time-to-peak } \\
\text { difference (ms) }\end{array}$ & Range (ms) \\
\hline P1 $(n=15)$ & 3 & $0.08 \pm 0.01$ & $0.04-0.15$ \\
& 4 & $0.06 \pm 0.01$ & $0.02-0.10$ \\
& 5 & $0.03 \pm 0.01$ & $0.00-0.08$ \\
& 8 & $0.01 \pm 0.01$ & -0.01 to 0.02 \\
P2 $(n=15)$ & 10 & $0.00 \pm 0.01$ & -0.01 to 0.02 \\
& 20 & $0.00 \pm 0.01$ & -0.01 to 0.00 \\
& 3 & $0.37 \pm 0.03$ & $0.21-0.66$ \\
P3 $(n=11)$ & $0.23 \pm 0.03$ & $0.12-0.44$ \\
& 5 & $0.16 \pm 0.02$ & $0.07-0.31$ \\
& 10 & $0.07 \pm 0.01$ & $0.01-0.13$ \\
& 20 & $0.04 \pm 0.01$ & -0.02 to 0.08 \\
& 3 & $0.00 \pm 0.01$ & -0.07 to 0.02 \\
& 4 & $0.62 \pm 0.07$ & $0.27-1.02$ \\
& 5 & $0.40 \pm 0.04$ & $0.17-0.65$ \\
& 8 & $0.27 \pm 0.03$ & $0.15-0.47$ \\
& 10 & $0.15 \pm 0.02$ & $0.07-0.32$ \\
& 20 & $0.09 \pm 0.01$ & $0.03-0.15$ \\
& & $0.02 \pm 0.01$ & -0.05 to 0.11 \\
\hline
\end{tabular}

Stimulus pulses were presented as pairs, the first and second eliciting a cardinal (C) and follower (F) CAP, respectively. The $C-F$ difference for each ISI is the mean \pm SEM of the differences between the time-to-peak of the P1, P2, and $\mathrm{P} 3$ peaks in the $\mathrm{C}$ and $\mathrm{F}$ CAPs recorded from each of the indicated number of optic nerves.

the P1, P2, and P3 time-to-peak values of the test CAP increased (Fig. $1 B$ ). Increasing the number of conditioning CAPs produced further increases (Fig. 1B). Therefore, our recordings show a slowing effect that increases gradually and accumulates. Moreover, the slowing effect appears to asymptote after 50-300 ms of conditioning stimulation; that is, increasing the number of conditioning CAPs from 3 to 16 produced smaller increases in the slowing effect than increasing the conditioning CAP number from 1 to 3 (Fig. 1B). Repeated CAPs at lower frequencies (e.g., $10-20 \mathrm{~Hz}$ ) did not induce slowing of test CAPs even if relatively large numbers of conditioning pulses were used. Also, we did not find that conditioning pulses decrease the time-to-peak of follower CAPs. This is of interest because studies of other systems have reported that spikes increase the conduction velocity of some axons during transient "supernormal" phases (Swadlow et al., 1980; Taylor et al., 1992) and that spikes reduce conduction velocity without supernormal increases in other preparations (Lüscher et al., 1994; George et al., 2007; Meeks and Mennerick, 2007).

\section{Change in interspike interval and instantaneous spike frequency}

Because the distance traveled by cardinal and follower spikes are the same, spike-induced increases in time-to-peak are consistent with the possibility that follower spikes propagate more slowly than cardinal spikes (Fig. 1). Due to this slowing, the interspike interval between cardinal and follower spikes at the recording electrode in single axons would be longer than the ISI at the stimulating electrode.

The changes in time-to-peak shown in Figure 1 were measured in segments of optic nerve that averaged $8 \mathrm{~mm}$ in length. In adult rat, the optic nerve length from the rear of the eye to the optic chiasm is $\sim 10 \mathrm{~mm}$ (Matheson, 1970) and the optic tract length from the chiasm to the lateral geniculate nucleus (LGN) is 9-10 mm (Sumitomo et al., 1969). To estimate how much the interspike interval between cardinal and follower spikes might increase between the eye and a subcortical brain target, we assumed a distance of $20 \mathrm{~mm}$ from eye to LGN, that follower spike delays increase linearly with distance, and that adding the delays and stimulus intervals yields the cardinal-follower spike intervals at the LGN. Inverting these sums to express the changes in units of instantaneous spike frequency $(\mathrm{Hz})$ yields values of 313, 255, and $220 \mathrm{~Hz}$ for P1, P2, and P3, respectively, at a stimulus interval of $3 \mathrm{~ms}(333 \mathrm{~Hz}) ; 197,185$, and $176 \mathrm{~Hz}$ at a stimulus interval of $5 \mathrm{~ms}(200 \mathrm{~Hz})$, and 100,99 , and $98 \mathrm{~Hz}$ at an interval of $10 \mathrm{~ms}$ $(100 \mathrm{~Hz})$. This suggests that optic tract spike frequencies will increase as stimulus frequencies increase $>100 \mathrm{~Hz}$, although not as much as RGC spike frequencies, and that stimulus frequencies and optic tract spike frequencies will not noticeably differ at $<100 \mathrm{~Hz}$. These results would not change qualitatively if the distance between the eye and target were a few millimeters longer or shorter than $20 \mathrm{~mm}$. However, if the distance is a few-fold different (e.g., $100 \mathrm{~mm}$, as in human; Lang and Reiter, 1985; Bernstein et al., 2016), then spike slowing could depress the instantaneous spike frequency at the shortest stimulus intervals more than at intermediate stimulus frequencies.

Beside slowing of propagation, spiking might appear to increase interspike intervals for two other reasons. One is that a cardinal spike might increase the "rise time" between the beginning of the depolarizing phase of a follower spike and the moment the follower spike reaches its peak (Meeks and Mennerick, 2007). Although we could not directly test this possibility on single axons in optic nerve, we could elicit and record axonal spikes on multielectrode arrays. When pairs of pulses at one electrode elicited pairs of spikes at a recording electrode a few hundred micrometers away, the latencies from the stimulus to the beginning of the two spikes elicited were indistinguishable. We also detected no difference in the rise times of cardinal and follower spikes in the recordings from some of these electrode pairs. However, on other electrode pairs, the follower spike rise times increased at high pulse frequencies. For example, at an ISI of $5 \mathrm{~ms}$, the rise time of the follower spikes was as much as $0.28 \mathrm{~ms}$ longer than that of the cardinal spikes. Because we could not measure the length of axons that these measurements were made from, we could not identify which recordings corresponded to P1, P2, and P3 of the CAPs. Nonetheless, the changes that we measured ( $0-$ $0.28 \mathrm{~ms}$ ) are smaller than the increases in time-to-peak values of $\mathrm{P} 2$ and $\mathrm{P} 3$ in the CAPs $(0.07-0.31 \mathrm{~ms}$ and $0.15-0.47 \mathrm{~ms}$, respectively; Table 1) and as small as the increases found in P1 (0.00$0.08 \mathrm{~ms}$, Table 1).

A second possible reason is that, among the axons that contribute to a single CAP peak, the firing of more rapidly conducting axons might be suppressed by the first stimulus and the firing of more slowly conducting axons might either be spared or further slowed. This seems unlikely because recordings of isolated CAP peaks in optic tract (by recording from positions populated by axons of relatively uniform diameters) have shown that spikeinduced changes in time-to-peak do not split peaks into more rapidly and slowly propagating subgroups (Bishop et al., 1953). However, we cannot yet exclude this possibility for optic nerve. We used various fine-tipped metal and glass electrodes to record from optic nerve, but did not capture isolated peaks. This is presumably because axons of different diameter are not segregated into different layers or sectors within the rat optic nerve (Figs. 2, 3; see also Sugimoto et al., 1984; Reese, 1987).

\section{Autophosphorylated CaMKII in rat optic nerve}

Previous reports of voltage-gated $\mathrm{Ca}^{2+}$ channels and CaMKII in rat optic nerve (Brown et al., 2001; Lund and McQuarrie, 2001) raise the possibility that pT286 might be present under certain conditions and thus positioned to modulate the excitability of RGC axons. We began to test this possibility by probing Western 
A

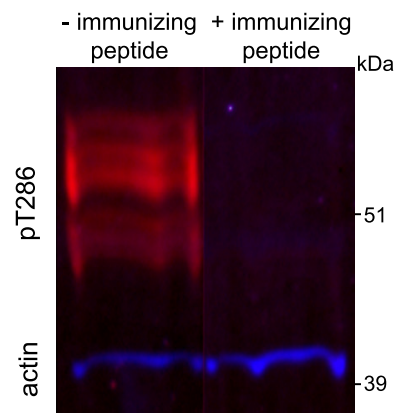

B

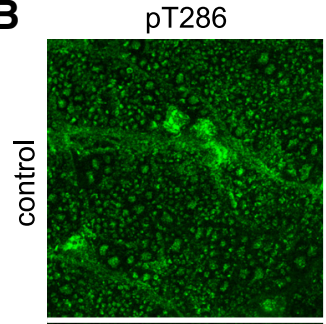

SMI-312

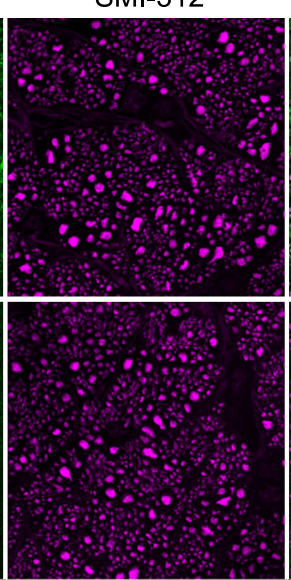

merge

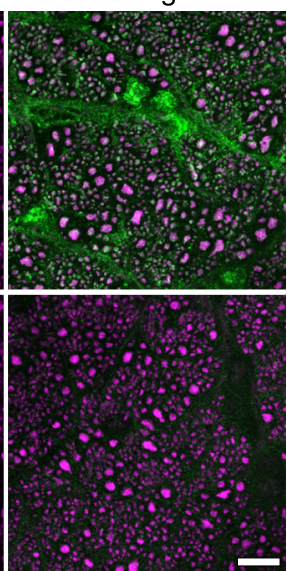

Figure 2. pT286-immunopositive optic nerve protein bands and axons, and reduction of pT286 staining intensity by immunizing peptide. $\boldsymbol{A}$, Western blots of a rat optic nerve, processed side-by-side in adjacent lanes. Left lane, " - immunizing peptide" probed with anti-pT286 (red) and anti- $\beta$-actin (blue) antibodies. Right lane, " + immunizing peptide" probed with anti- $\beta$-actin antibody and anti-pT286 antibody that was preincubated with immunizing peptide. The latter shows no detectable pT286 signal above background intensity. Molecular weight and migration distance of protein standards that were run in an adjacent lane are shown at right edge of $\boldsymbol{A}$. $\boldsymbol{B}$, Transverse sections of an optic nerve processed side-by-side and imaged at identical laser intensity, photomultiplier gain, and pinhole diameter. Left, middle, and right panels of top row show pT286 (green), SMl-312 (magenta), and merge thereof, respectively. pT286 detected in axons (round, SMI-312-immunopositive profiles) and in baffle-like structure filling dark, SMI-312-immunonegative region between clusters of SMI-312-immunopositive profiles. Left, middle, and right panels of bottom row show green only (anti-pT286 antibody that was preincubated with immunizing peptide), magenta only (SMI-312), and merge thereof, respectively. This row shows no detectable pT286 signal above background intensity. Scale bar at lower right in $\boldsymbol{B}$ indicates $10 \mu \mathrm{m}$ and applies to all panels.

blots of optic nerve homogenates with an anti-pT286 antibody and by immunostaining transverse and longitudinal sections of optic nerve for pT286. Both the rabbit polyclonal and the rabbit monoclonal anti-pT286 antibodies used bound to three protein bands in these blots, with apparent molecular weights of $\sim 49,53$, and $55 \mathrm{kDa}$ (Fig. 2A). These values agree well with those found in other preparations (Matsuyama et al., 2014; Sheng et al., 2015). No staining above background was detectable in Western blots with primary antibody that was preincubated with an excess of immunizing peptide (Fig. 2A). Opposite staining patterns were obtained when adjacent lanes were stained with blocked and unblocked primary antibody, stripped of primary and secondary antibodies with a stripping buffer, and then restained with the antibodies switched (e.g., blocked antibody applied to the lane that had been bound by unblocked antibody before stripping). Moreover, antibodies directed against the $\alpha$ isoform (CaMKII- $\alpha$ ) bound to the 49 and $53 \mathrm{kDa}$ bands in our blots, as found in blots prepared from retina, hippocampus, and cerebellum (Ochiishi et al., 1994; Laabich and Cooper, 1999; Liu et al., 2000; Menegon et al., 2002). In blots stained with some anti-CaMKII antibodies, the immunofluorescence intensity of the $49 \mathrm{kDa}$ band exceeded that of the other bands (Fig. 4A).

Within the optic nerve, an anti-pT286 antibody (rabbit polyclonal directed against an amino acid sequence that surrounds and includes the pT286 of CaMKII- $\alpha$ ) bound to round, elongated profiles (Figs. 2, 3). These profiles were identified as axons because they also bound antibody directed against pan axonal neurofilaments (SMI-312; Ulfig et al., 1998). All, or very nearly all, of the SMI-312-immunopositive axons were pT286-immunopositive and we did not notice a size, number, or distribution of axons that consistently lacked pT286 immunopositivity. The pT286- and SMI-312-immunopositive profiles ranged in diameter from $\sim 0.3$ to $4.3 \mu \mathrm{m}$ in both transverse (Fig. $3 \mathrm{H}$ ) and longitudinal (Fig. 3A) sections. This diameter range agrees with previously reported dimensions of rat optic nerve axons (Forrester and Peters, 1967; De Juan et al., 1978; Foster et al., 1982; Sugimoto et al., 1984; Reese, 1987). The mean and median values of the diameters were 1.0 and $0.8 \mu \mathrm{m}$, respectively $(n=390$ axon profiles from a total of eight optic nerves). No immunostaining above background was detectable with primary antibody that was preincubated with an excess of immunizing peptide (Fig. 2B). Moreover, a different antibody (rabbit monoclonal, directed against an amino acid sequence that surrounds and includes the phosphorylated T287 of CaMKII- $\beta$ ) produced similar staining of SMI-312-immunopositive profiles in longitudinally and transversely sectioned preparations.

In preparations triple-labeled for pT286, SMI-312, and MBP (Dixon and Eng, 1984), pT286 was found in SMI-312-immunopositive profiles and not in MBP-immunopositive profiles (Fig. 3). Moreover, cylindrical, pT286-immunopositive profiles were circumscribed by annular, MBP-immunopositive profiles (Fig. $3 H$ ). The MBP-immunopositive annuli that we could measure in our confocal images ranged in outer diameters between 1.2 and $4.9 \mu \mathrm{m}$ (mean $\pm \mathrm{SEM}=2.6 \pm 0.1 \mu \mathrm{m} ; n=164)$. These values are intermediate between light and electron microscopically measured values reported previously for rat (Forrester and Peters, 1967; Matheson, 1970). The ratio of the diameter of each pT286immunopositive profile to the outer diameter of the MBPimmunopositive profiles that circumscribed it (g-ratio; Fig. $3 P$ ) ranged between 0.4 and 0.8 , and averaged $0.7 \pm 0.1$ (mean \pm SEM, $n=164$ ). Our images also suggested that smaller-diameter MBP-immunopositive annuli were present (arrowheads in Fig. $3 H$ ). However, the outer and inner diameters of these were too small for us to measure. We also could not resolve whether any fibers lacked MBP-immunopositive annular wrappings, especially small fibers that might correspond to the unmyelinated fibers reported by other studies (Foster et al., 1982; Sugimoto et al., 1984).

\section{Net reduction of pT286 levels by flickering illumination and by spiking}

Based on changes in the intensity and location of arrestin, transducin, and cAMP immunostaining in photoreceptors and of cAMP in retinal ganglion cells, we previously found that flicker- 

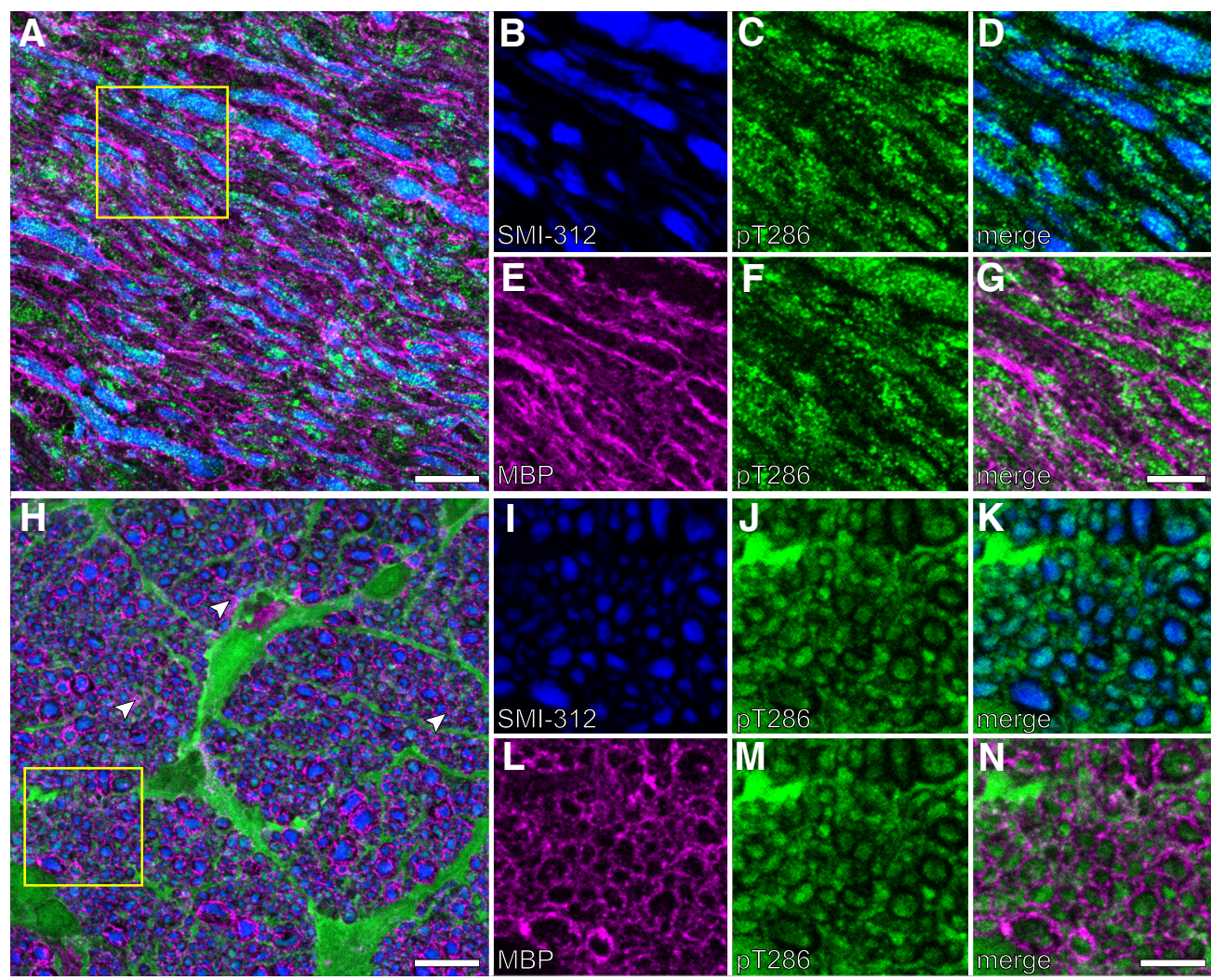

0

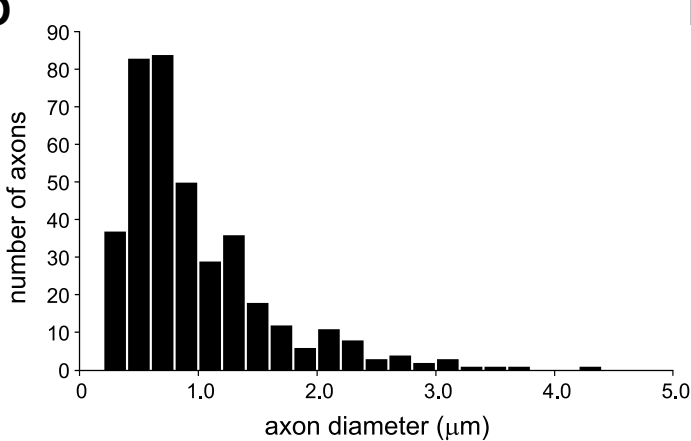

P

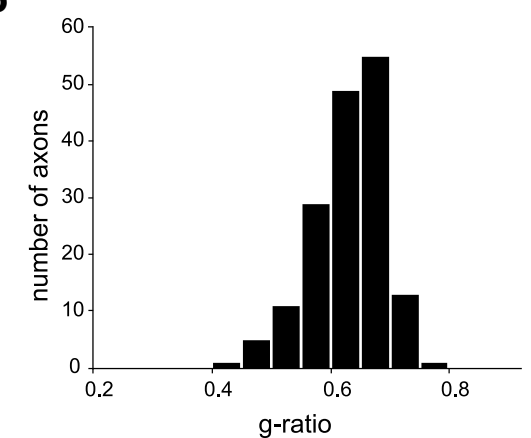

Figure 3. Diameters and myelin of pT286-immunopositive optic nerve axons. Longitudinal ( $\boldsymbol{A}$ ) and transverse ( $\boldsymbol{H}$ ) sections triple-labeled for SMI-312 (blue), pT286 (green), and MBP (magenta). $\boldsymbol{B}-\boldsymbol{D}$, SMI-312 (B) and pT286 ( $)$ of the area within the yellow square in $\boldsymbol{A}$ and merge thereof $(\boldsymbol{D})$. SMI-312 and pT286 colocalization generates cyan. $\boldsymbol{E}-\boldsymbol{G}, \mathrm{MBP}(\boldsymbol{E})$, pT286 ( $\boldsymbol{F})$, and merge thereof $(\boldsymbol{G})$ of the same field as $\boldsymbol{D}$. Separation of magenta and green in $\mathbf{G}$ shows that pT286 localizes to axons and not to myelin. The axon diameters (e.g., $\boldsymbol{A}$ and $\mathbf{G})$ range between small and large. $\boldsymbol{H}-\boldsymbol{N}$, Comparable information in cross-section, including colocalization (cyan in $\boldsymbol{K})$ of SMI-312 $(\boldsymbol{I})$ and pT286 $(\boldsymbol{J})$, separation $(\boldsymbol{N})$ of MBP $(\boldsymbol{L})$ and pT286 $(\boldsymbol{M})$, and wide range of axon diameters $(\boldsymbol{N})$ and inner diameter of myelin sheaths $(\boldsymbol{L})$. $\boldsymbol{I}-\boldsymbol{N}$, Field outlined by yellow square in $\boldsymbol{H}$. Scale bars: $\boldsymbol{A}, \boldsymbol{H}, 10 \mu \mathrm{m} ; \boldsymbol{G}, 5 \mu \mathrm{m}$ (applies to $\boldsymbol{B}-\boldsymbol{G}$ ); $\boldsymbol{N}, 5 \mu \mathrm{m}$ (applies to $\boldsymbol{I}-\boldsymbol{N}$ ). Histograms of axon diameters ( $\mathbf{0}$ ) and g-ratio ( $\boldsymbol{P}$; ratio of inner and outer diameters of MBP-immunopositive profiles) of optic nerves of which $\boldsymbol{A}$ and $\boldsymbol{H}$ are part.

ing illumination light adapts adult rat retinae and increases pT286 immunostaining intensity in rat RGC somata (Ogata et al., 2012). Because CaMKII can be detected in optic nerve (Lund and McQuarrie, 2001; Calkins et al., 2005), electrically stimulated spiking elevates free $\mathrm{Ca}^{2+}$ levels in optic nerve axons (Lev-Ram and Grinvald, 1987; Verbny et al., 2002) and alternating increments and decrements of illumination increases spike firing in RGCs (Hartline, 1938; Baden et al., 2016), we anticipated that flickering illumination and electrical stimulation would increase pT286 immunostaining intensity in the optic nerve.

Contrary to these expectations, flickering illumination (for details, see Materials and Methods) lowered the staining intensity of the pT286-immunopositive protein bands in Western blots (Fig. 4). Because illumination reduced the intensity of all three pT286-immunopositive bands ( $\sim 49,53$, and $55 \mathrm{kDa}$; Fig. $4 A, B)$, the scatter plot and bar graph in Figure 4, $C$ and $D$, compare the sum of the intensities of the bands in the dark versus light. The fluorescence intensities of these bands normalized to that of loading control protein in each lane were $20 \pm 7 \%$ higher (mean \pm SEM, $n=9$ ) in the blots prepared from dark-adapted rat optic nerves than in those of concomitantly collected and processed light-adapted rat optic nerves. The mean intensities differed significantly (Fig. 4D, Wilcoxon signed-rank test, $p=0.04$ ) and there was no statistically significant light/dark staining intensity difference between the CaMKII-immunopositive bands in the same blots (Wilcoxon signed-rank test, $p=0.78$; Fig. $4 D$ ).

Similarly, the average of the fluorescence intensities of the pT286-immunopositive protein bands in a given blot lane normalized to that of the loading control protein was $30 \pm 5 \%$ lower (mean \pm SEM, $n=10$ ) in the blots prepared from electrically 
A

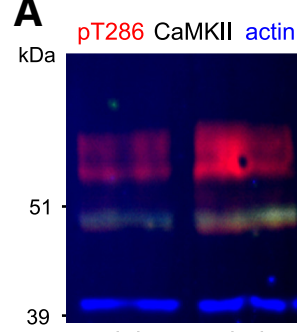

light

dark

\section{B}

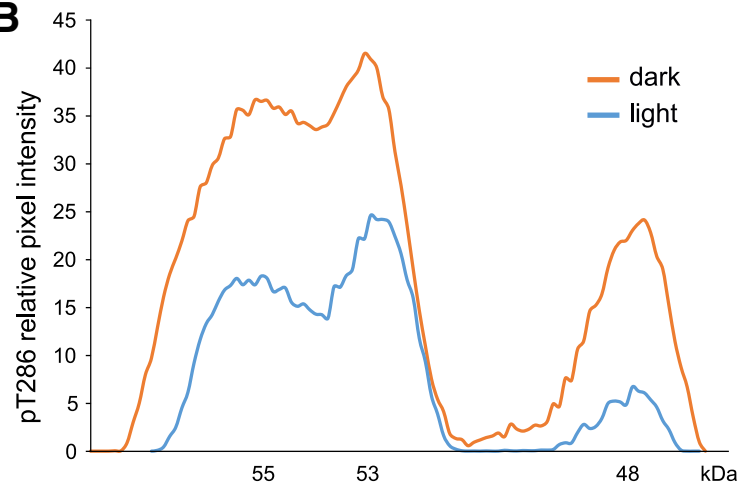

\section{C}

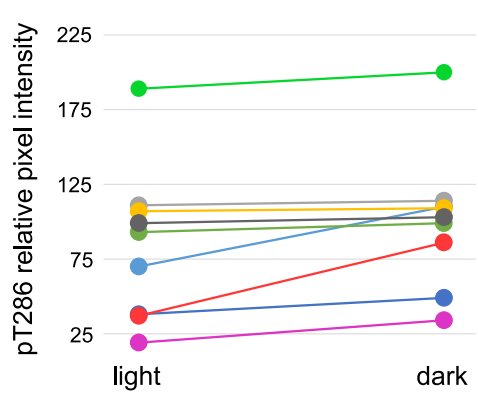

D

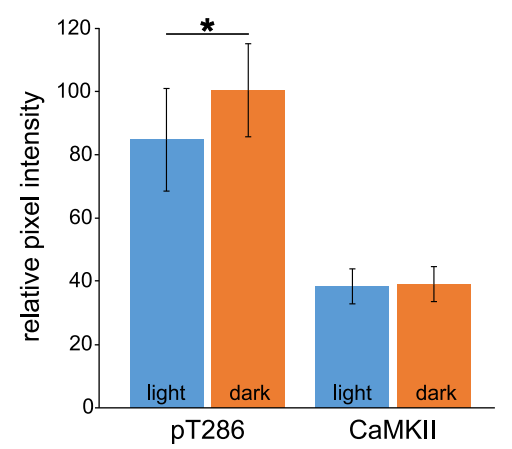

Figure 4. Illumination reduces optic nerve pT286 signal intensity. A, Western blot prepared from optic nerves of dark- and light-adapted rats collected, processed, and probed in pairs with antibodies directed against pT286 (red), CaMKII (gray), and $\beta$-actin (blue). The left, middle, and right pairs of lanes show all signals superimposed (red, gray, and blue color channels), pT286 signals only (red), and CaMKII signals only (gray), respectively. Molecular weight and migration distance of protein standards run in adjacent lane shown at left edge of $\boldsymbol{A}$. $\boldsymbol{B}$, pT286 pixel intensity in $\boldsymbol{A}$ normalized by $\beta$-actin band pixel intensity and plotted against estimated apparent molecular weight. The two tallest peaks correspond to the two bright bands $>50 \mathrm{kDa}$ in $A$. C, pT286 pixel intensity in Western blots of optic nerves collected from pairs $(n=9)$ of light- and dark-adapted rats. The average of the fluorescence intensities of the pT286 bands in each blot was normalized by the fluorescence intensity of the $\beta$-actin band in each lane. Values from each rat pair are plotted by dots of same color and connected by lines. $D$, Mean signal intensities ( \pm SEM) of pT286 and CaMKII bands for the nerves as in $\boldsymbol{C}$. pT286 signal variance is relatively large because light decreased the signal intensity in some preparations more than in others $(\boldsymbol{B})$. However, the difference between means is statistically significant ( ${ }^{*}$, Wilcoxon signed-rank test, $\left.p=0.04\right)$. In $\boldsymbol{A}-\boldsymbol{D}$, "light" and "dark" denote light- and dark-adapted, respectively.
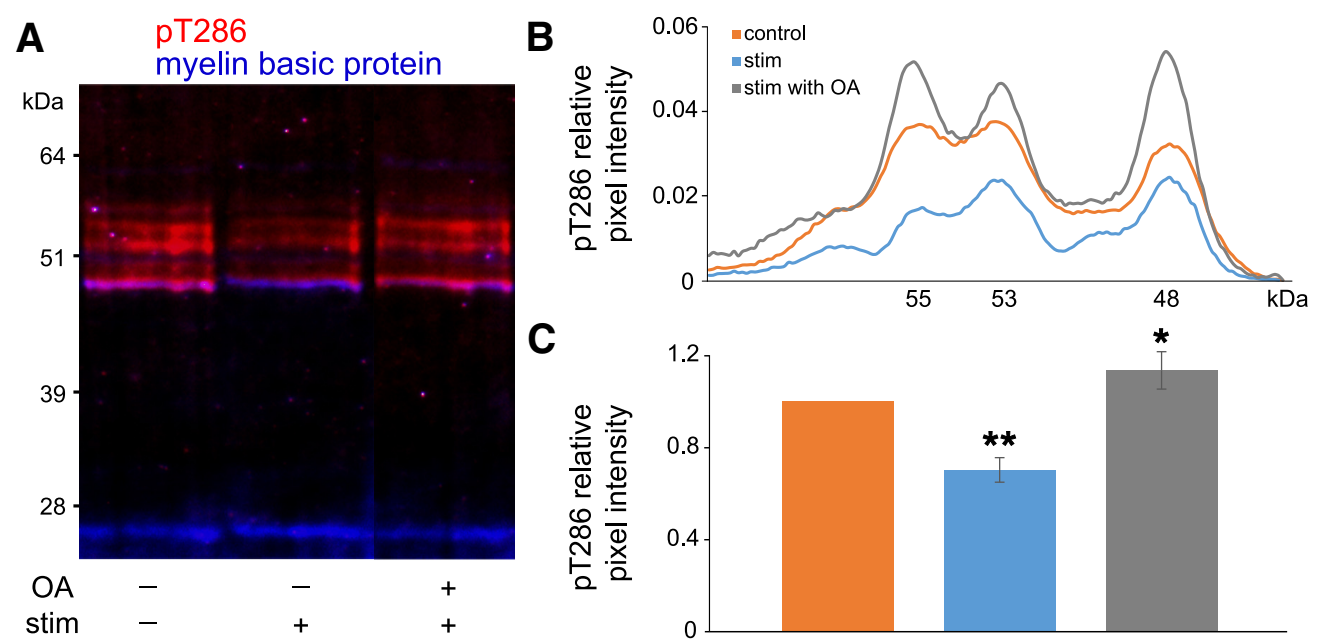

Figure 5. Okadaic acid increases optic nerve pT286 signal intensity. $\boldsymbol{A}$, Western blots prepared from optic nerves that were electrically stimulated or not in the presence and absence of okadaic acid (as indicated by the lane labels below the blot lanes). Blots were probed with antibodies directed against pT286 (red) and MBP (blue). Molecular weight and migration distance of protein standards run in adjacent lane shown at left edge. $\boldsymbol{B}$, Relative pixel intensity of pT286 signals in $\boldsymbol{A}$ normalized by pixel intensity of MBP bands and plotted against estimated apparent molecular weight. $\boldsymbol{C}$, Relative pixel intensity of pT286 signals from $n=3$ optic nerves processed and analyzed as in $\boldsymbol{A}$ and $\boldsymbol{B}$. Differences between fluorescence intensity of protein bands from control and electrically stimulated optic nerves $(* *)$ and between those of control nerves and nerves stimulated in the presence of okadaic acid $(*)$ are statistically significant ( $p=0.002$ and 0.025 , respectively).

stimulated optic nerves (for details, see Materials and Methods) than in those of concomitantly processed optic nerves that were not stimulated (Fig. 5). The unstimulated nerves were positioned between stimulating and recording electrodes and maintained under identical conditions except that electrical stimuli were not delivered. The difference between these fluorescence intensities was statistically significant (Wilcoxon signed-rank test, $p=$ 0.002; Fig. 5C).

The T286 of CaMKII is autophosphorylated during activation by $\mathrm{Ca}^{2+} /$ calmodulin complexes (Lisman et al., 2002) and can be dephosphorylated by protein serine/threonine phosphatases (Ishida et al., 2003). Therefore, one possible explanation for the 
A

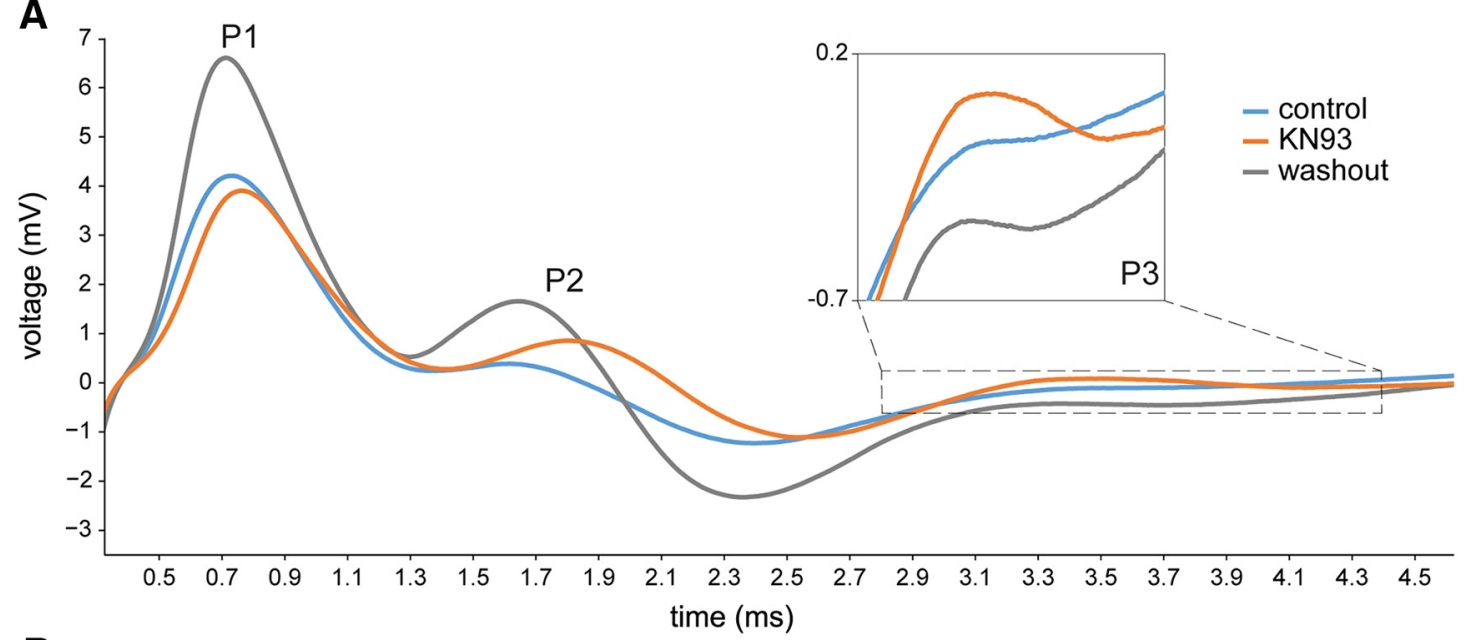

B
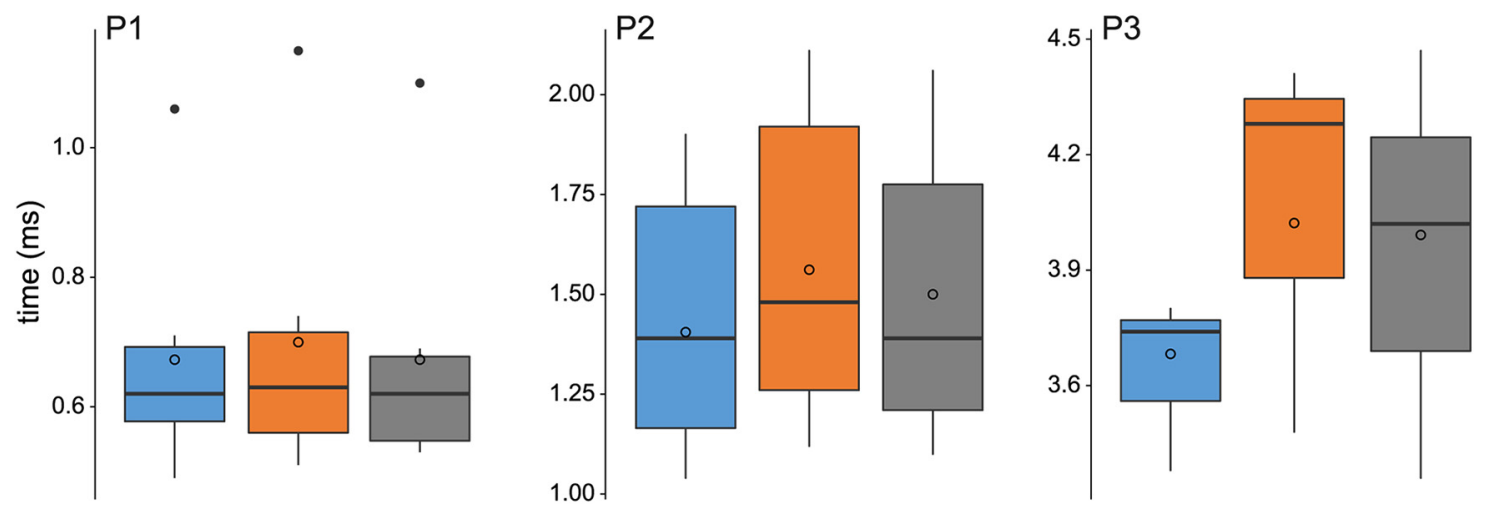

Figure 6. KN93 reversibly increases time-to-peak of optic nerve spikes. $A$, CAP recorded before (blue) and during (orange) inclusion of $2 \mu M$ KN93 in medium superfusing an optic nerve and after washing with control medium (gray). Inset shows magnified view of P3. B, Box plots of the effect of KN93 on time-to-peak and its reversibility (same color coding as in $\boldsymbol{A}$ ). These show the median (thick horizontal line), mean (circle), interquartile range (IQR, box), largest and smallest values no further than $1.5 *$ IQR from the box (vertical lines) and outliers (single dots). The difference between the P2 time-to-peak in control and KN93 is statistically significant $(p=0.015)$.

illumination- and spiking-induced decrease in pT286 is that spiking activates a protein phosphatase that dephosphorylates the basal level of pT286. A second possibility is that spiking decreases CaMKII autophosphorylation and that a constitutively active protein phosphatase dephosphorylates the basal level of pT286. A third possibility is that spiking increases both CaMKII autophosphorylation and a protein phosphatase activity that dephosphorylates pT286 and that the net effect that can be detected by Western blots is a decrease in pT286 levels. Of these possibilities, the pT286 immunostaining intensities of Western blots normalized by the loading control protein staining intensities (Fig. 5A) showed effects that are consistent with the third. The simplest interpretations of the electrically stimulated decrease in pT286 (Fig. $5 A-C$ ) are that constitutive phosphorylation helps set the pT286 level in unstimulated optic nerve and that stimulation increases phosphatase activity. Moreover, the pT286 signal during electrical stimulation in the presence of okadaic acid $(0.4 \mu \mathrm{M})$ exceeds that in resting optic nerves by $17 \pm 7 \%$ (mean \pm SEM, $n=10$; Fig. $5 A-C$ ). The difference between these intensities was statistically significant (Wilcoxon signed-rank test, $p=0.025$ ). This suggests that electrical stimulation increases CaMKII autophosphorylation in addition to increasing phosphatase activity and that dephosphorylation outweighs autophosphorylation in control medium.

\section{Decreasing CaMKII autophosphorylation decreases the speed of spike propagation}

Because repetitive stimulation slows spike propagation (Fig. 1) and lowers the pT286 fluorescence intensity in Western blots (Fig. 5), we next tested whether spike time-to-peak is affected by a water-soluble inhibitor of $\mathrm{Ca}^{2+} /$ calmodulin binding to CaMKII (KN93; Sumi et al., 1991). We compared CAPs recorded from optic nerves superfused with control medium, control medium supplemented with $\mathrm{KN} 93(2 \mu \mathrm{M})$, and control medium again, each for 20-60 min. KN93 increased the P1, P2, and P3 time-to-peak values of CAPs activated by single pulses to $103 \pm$ $2 \%, 109 \pm 1 \%$, and $111 \pm 4 \%$ of the control values, respectively (mean \pm SEM of the changes measured nerve-by-nerve; $n=6$, $n=7$, and $n=3$, respectively; Fig. 6). Washing with control medium decreased the $\mathrm{P} 1, \mathrm{P} 2$, and $\mathrm{P} 3$ values of the same nerves to $100 \pm 2 \%, 104 \pm 1 \%$, and $108 \pm 6 \%$ of the control values, respectively. Box plots (Fig. 6B) show that the median, mean, and majority of the time-to-peak values increased in KN93 and recovered at least partially during subsequent washing. The difference between the time-to-peak values (pooled across P1, P2, and P3) was statistically significant between control and KN93 ( $p=$ $0.00036)$ and between KN93 and wash ( $p=0.0065$, both Wilcoxon signed-rank test, $n=16$ ). The difference between the measurements in control and KN93 was statistically significant for P2 


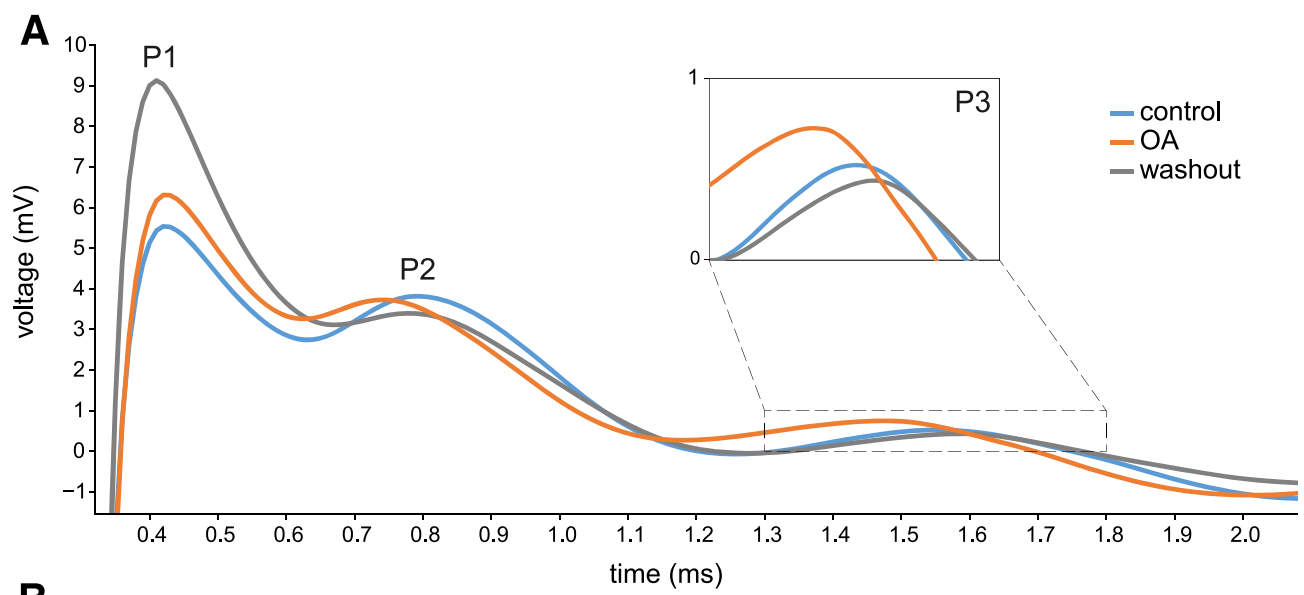

B
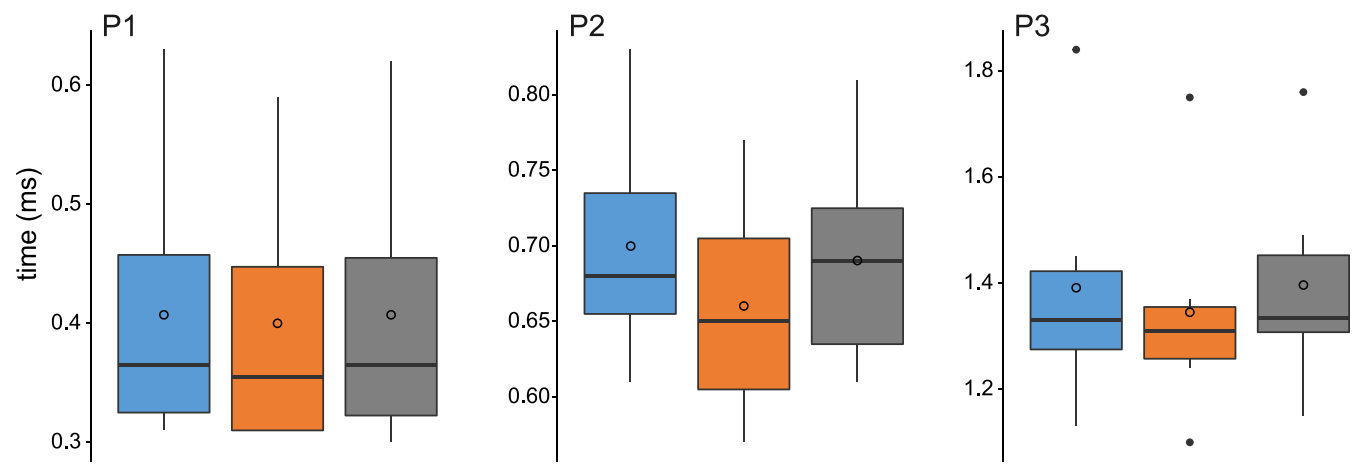

Figure 7. Okadaic acid reversibly decreases time-to-peak of optic nerve spikes. $A$, CAP recorded before (blue) and during (orange) inclusion of $0.4 \mu \mathrm{M}$ okadaic acid in medium superfusing an optic nerve and after washing with control medium (gray). Inset shows magnified view of P3. B, Box plots of the effect of okadaic acid on time-to-peak and its reversibility in same color-coded conditions as in $\boldsymbol{A}$. These show the median (thick horizontal line), mean (circle), interquartile range (IQR, box), largest and smallest values no further than $1.5 *$ IQR from the box (vertical lines), and outliers (single dots).

(Wilcoxon signed-rank test, $p=0.015$ ) and KN93 slowed P1 slightly and slowed P3 more than P2 or P1. However, the differences for P1 and P3 did not reach statistical significance due to small sample sizes.

Some previous studies used KN93 solubilized in dimethylsulfoxide (DMSO) to inhibit CaMKII. We found that DMSOsolubilized KN93 produced inconsistent (and, in some nerves, irreversible) changes in spike interval (result not illustrated). This is consistent with reports that DMSO-solubilized KN93 can produce nonspecific effects (Ledoux et al., 1999; Gao et al., 2006) and that DMSO is not an inert vehicle (Tamagnini et al., 2014). Based on these results, we did not test for the effects of other DMSOsolubilized reagents (e.g., KN92 and KN62).

\section{Increasing CaMKII autophosphorylation increases the speed of spike propagation}

We next tested whether increasing CaMKII autophosphorylation speeds up spike propagation. Given that okadaic acid and fostriecin inhibit protein phosphatase isoforms that dephosphorylate pT286 in various preparations (Ishida et al., 2003), CAPs were recorded from optic nerves superfused with control medium, control medium supplemented with either okadaic acid or fostriecin, and then control medium again, each for 20-60 min.

Okadaic acid $(0.4 \mu \mathrm{M})$ reduced the $\mathrm{P} 1, \mathrm{P} 2$, and $\mathrm{P} 3$ time-topeak values in response to single pulses to $97 \pm 1 \%, 93 \pm 2 \%$, and $97 \pm 1 \%$ of the control values (mean of the changes measured nerve-by-nerve; $n=4, n=5$, and $n=4$, respectively; Fig. 7). Washing with control medium increased the mean P1, P2, and P3 values of the same nerves to $100 \pm 1 \%, 99 \pm 2 \%$, and $103 \pm 6 \%$ of the control values, respectively. Similarly, fostriecin $(1 \mu \mathrm{M})$ decreased the time-to-peak of P1, P2, and P3 to $96 \pm 1 \%, 94 \pm$ $2 \%$, and $92 \pm 3 \%$ of the control values, respectively, and washing increased these values to $102 \pm 2 \%, 103 \pm 1 \%$, and $99 \pm 5 \%$ of the control values, respectively (mean, $n=6, n=6$, and $n=5$, respectively; Fig. 8). Box plots show that the median, mean, and range of the time-to-peak values shifted to lower values in okadaic acid (Fig. 7B) and in fostriecin (Fig. 8B) and recovered during subsequent washes. Wilcoxon signed-rank tests indicated that the decreases in time-to-peak of P2 and P3 by okadaic acid and the decrease in time-to-peak of $\mathrm{P} 2$ by fostriecin were statistically significant (Wilcoxon signed-rank test, $p$-values of 0.0223 , 0.0313 , and 0.0355 , respectively). Although fostriecin decreased the time-to-peak of P1 and of P3, the sample sizes did not allow calculations of Wilcoxon signed-rank statistics for those peaks. Also, the latency of P1 was so short (typically $0.5 \mathrm{~ms}$ ) that it would have been difficult to detect changes similar in magnitude (5$10 \%)$ to those we found in P2 and P3.

To test whether a phosphatase inhibitor counteracts activityinduced slowing of spikes, we measured the time-to-peak of cardinal CAPs and of F3 CAPs (i.e., those elicited after three conditioning pulses; $\mathrm{cf}$. Fig. $1 B$ ) before and during the application of fostriecin $(1 \mu \mathrm{M})$ and after washing with control medium (Fig. 9A,B). These CAPs were elicited by trains of $4-5$ pulses presented at an ISI of $5 \mathrm{~ms}$ with a 1-s pause between trains. Each cardinal CAP and F3 CAP was thus preceded by a 1-s and 5-ms stimulus interval, respectively. We calculated slowing as the dif- 


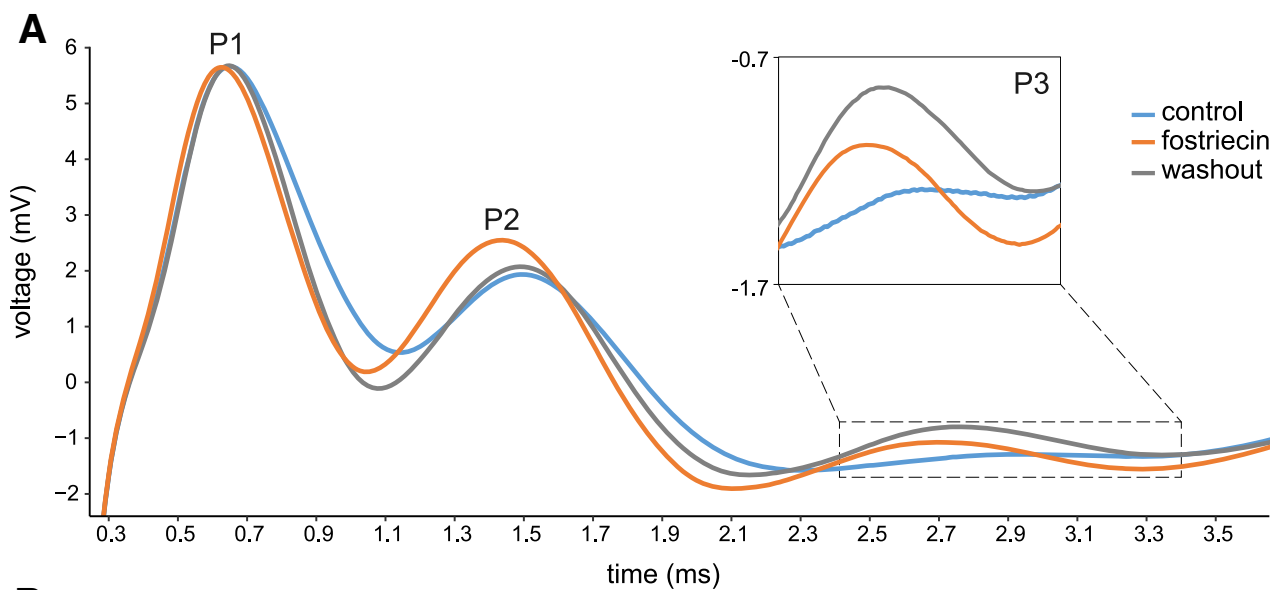

B
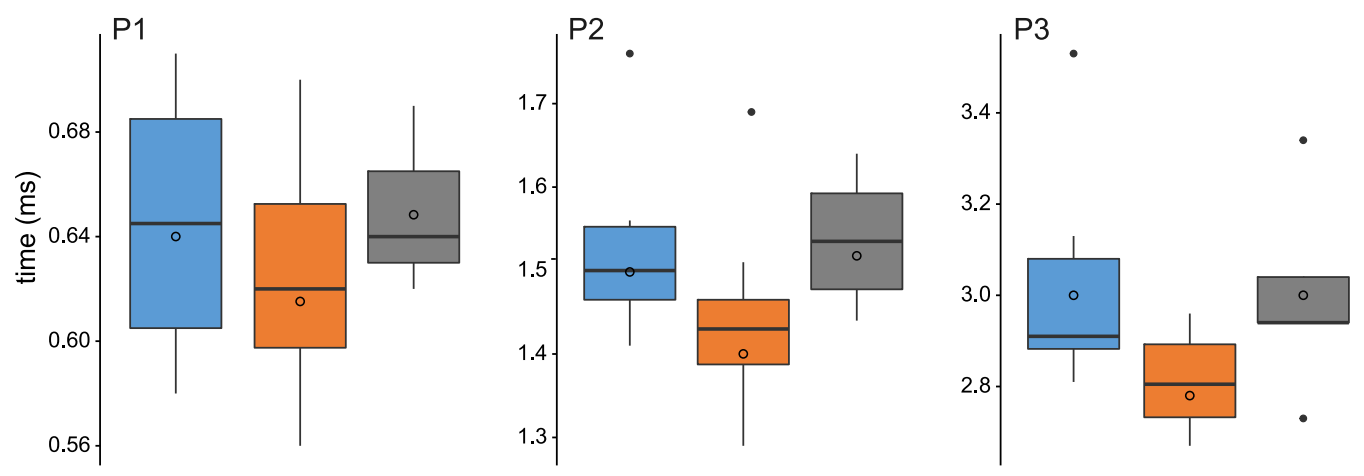

Figure 8. Fostriecin reversibly decreases time-to-peak of optic nerve spikes. $A$, CAP recorded before (blue) and during (orange) inclusion of $1 \mu M$ fostriecin in medium superfusing an optic nerve and after washing with control medium (gray). Inset shows magnified view of P3. B, Box plots of the effect of fostriecin on time-to-peak and its reversibility in same color-coded conditions as in $\boldsymbol{A}$. These show the median (thick horizontal line), mean (circle), interquartile range (IQR, box), largest and smallest values no further than $1.5 *$ IQR from the box (vertical lines), and outliers (single dots).

ference between the time-to-peak of the cardinal and F3 CAPs (Fig. 9C). Fostriecin reversibly reduced this difference for P1, P2, and $\mathrm{P} 3$. Fostriecin reduced the slowing to $91 \pm 15 \%, 73 \pm 19 \%$, and $71 \pm 15 \%$ of the control value, respectively. These reductions were statistically significant for $\mathrm{P} 2$ and $\mathrm{P} 3$ (Wilcoxon signed-rank tests, $p=0.016$ and $p=0.031$ and $n=8$ and $n=6$, respectively), but did not reach significance for P1 $(p=0.477, n=8)$. After washing, the slowing of P1, P2, and P3 were $107 \pm 5 \%, 106 \pm 3 \%$, and $112 \pm 2 \%$ of the control values, respectively. The differences between the values measured in fostriecin and wash were statistically significant (Wilcoxon signed-rank tests, $p=0.031, p=$ 0.008 , and $p=0.031$, and $n=8, n=8$, and $n=6$, respectively). As observed with okadaic acid (Fig. 5), the pT286 immunostaining intensity of Western blots prepared from optic nerves electrically stimulated in the presence of fostriecin $(1 \mu \mathrm{M})$ were greater than those of optic nerves that were electrically stimulated without fostriecin ( $n=2$; results not illustrated).

\section{Protein phosphatases in optic nerve}

Okadaic acid and fostriecin are commonly used to inhibit the protein phosphatase isoforms 1 and 2A (Bialojan and Takai, 1988; Walsh et al., 1997). We therefore attempted to localize these isoforms in transverse and longitudinal optic nerve sections by immunostaining with anti-PP1 and anti-PP2A antibodies. Preparations that were double-labeled for PP1 and MBP showed that optic nerve myelin bound anti-PP1 antibodies and that detectable levels of PP1 immunopositivity were not found in optic nerve axons (Fig. 10). This result is consistent with a previous report of PP1 in optic nerve homogenates (da Cruz e Silva et al.,
1995). By contrast, preparations that were triple-labeled for PP2A, MBP, and SMI-312 showed that axons bound anti-PP2A antibodies and that myelin did not (Fig. 11). Like the pT286immunopositive axonal profiles shown in Figure 3, the PP2Aimmunopositive axonal profiles ranged in diameter from small to large (Fig. 11). No previous study that we know of has detected $\mathrm{PP} 2 \mathrm{~A}$ in optic nerve axons.

\section{Activity-induced spike slowing in vivo}

Last, to test whether spike-induced spike slowing occurs in rat optic nerve in vivo, we used electrodes inserted into the optic chiasm to electrically stimulate spikes in ganglion cell axons and used a suction electrode to record these spikes from the optic nerve behind the eye. Stimuli were presented as a pair of pulses or as a train of 15 pulses with a fixed ISI separating the pulses. The pairs were repeated 13-14 times to form a series with a 2-s rest period between each pair. The trains were repeated the same way. For each ISI, 3 series of pairs were interleaved with 3 series of trains, resulting in 6 series $(2,15,2,15,2$, and 15) per preparation per ISI. This set of 6 series was first collected for the 5 -ms ISI, then for 8-ms ISI, and then for 30-ms ISI. (The CAP durations we found in vivo precluded tests of shorter stimulus intervals.) These recordings showed that both single and multiple conditioning pulses increased the time-to-peak values of the CAP waveforms recorded in the optic nerve (Fig. 12). As found in our recordings from excised optic nerves (Fig. 1), the degree of propagation slowing increased as the ISI decreased from 30 to $5 \mathrm{~ms}$ (gray vs orange vs blue lines in Fig. 12C,D) and as the number of conditioning pulses increased from 1 to 15 (gray, orange, and blue lines 

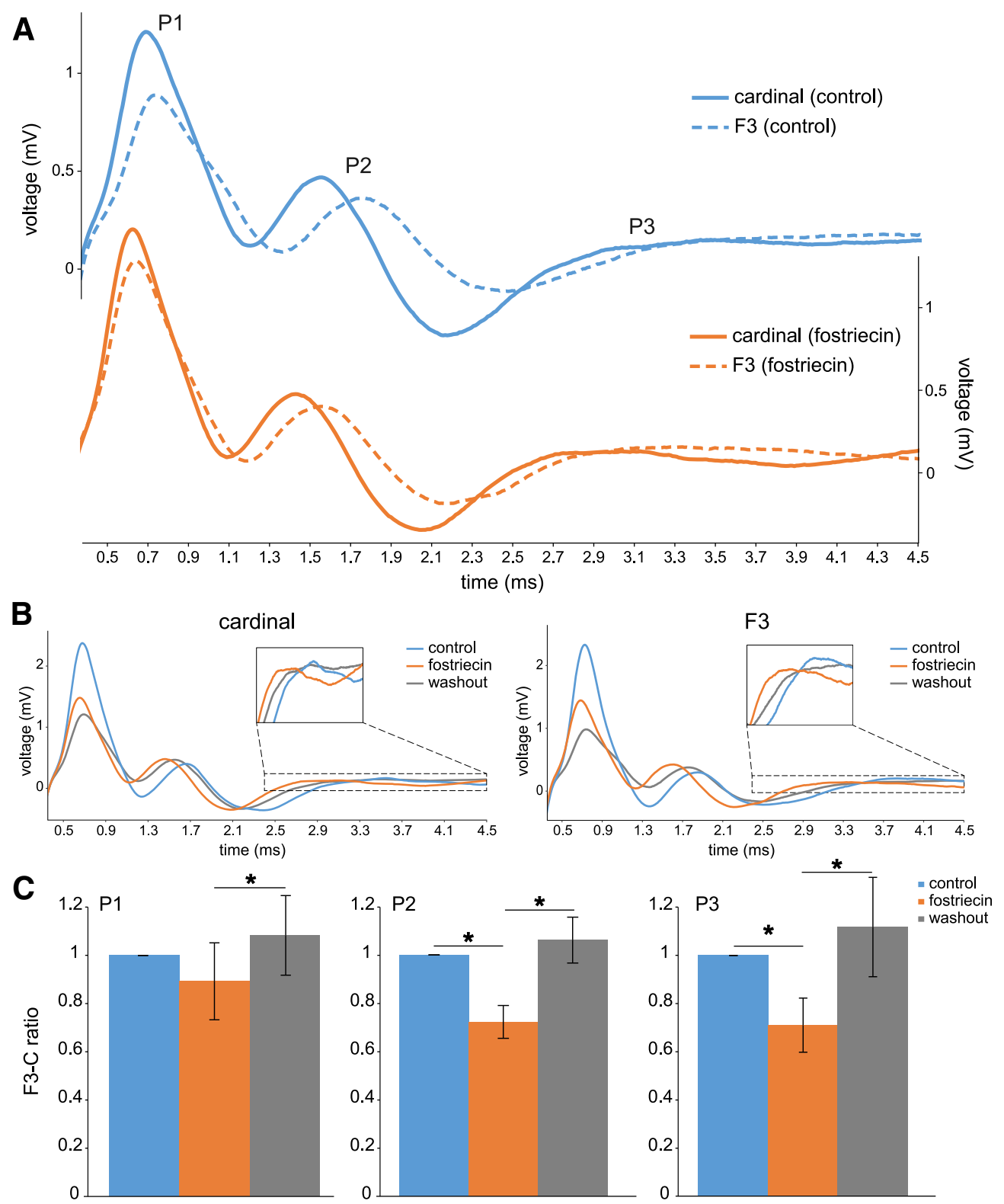

Figure 9. Fostriecin counteracts slowing by multiple conditioning pulses. A, CAPs elicited by the first (cardinal, C; continuous line) and fourth (F3; dotted line) of four pulses delivered at $200 \mathrm{~Hz}$ (5-ms ISI) in control (blue) and fostriecin (orange). B, Cardinal and F3 CAPs recorded before and during inclusion of $1 \mu \mathrm{M}$ fostriecin in medium superfusing the optic nerve and after washing with control medium. Digital average of $n=3-5$ CAPs recorded from one optic nerve in these media are plotted by blue, orange, and gray lines, respectively. C, Effect of fostriecin on the time-to-peak of the F3 CAPs normalized to those of the cardinal CAPs and its reversibility (same color coding as in B). The difference between control and fostriecin is statistically significant for P2 and P3 $\left({ }^{*}\right.$, Wilcoxon signed-rank, $p=0.0156$ and $p=0.0313$, respectively), but not for $\mathrm{P} 1$. The difference between fostriecin and the washes were significant for P1, $\mathrm{P} 2$, and P3 (*, Wilcoxon signed-rank; $p=0.0313, p=0.0078, p=0.0313$, respectively).

in Fig. $12 C, D)$. Also consistent with our ex vivo recordings, the increase in time-to-peak was larger for P2 than for P1 (Fig. 12D), the time-to-peak of both P1 and P2 was increased more by the first few conditioning pulses than later in long trains of pulses (Fig. 12C,D), and none of the conditioning pulses decreased the time-to-peak values. Our data showed these trends regardless of whether the time-to-peak values were measured at the maximum amplitude of the raw waveform (dots in Fig. $12 \mathrm{~A}, \mathrm{C})$ or at the maximum amplitude of Gaussian functions whose sums fitted the raw waveform (solid and dashed lines in Fig. $12 B, D$ ). These fits were used to estimate the time-to-peak values because distinct peaks were not well separated (cf. Fig. $1,8)$ and, instead, the in vivo CAPs resembled the waveforms elicited by high stimulus intensities in previous studies (Evans et al., 2010). By switching the recording and stimulating electrodes in one preparation, we also elicited CAPs in the optic nerve and recorded them in the optic chiasm. The time-topeak values of these orthodromically stimulated CAPs also increased at short ISI values. However, these CAPs were smaller in amplitude than the antidromically stimulated CAPs described above, rendering the orthodromic propagation changes more difficult to measure than the antidromic propagation changes.

\section{Discussion}

Our results show that rat optic nerves can modulate the propagation of the spikes that they generate. Specifically, we found that conditioning spikes and changes in CaMKII autophosphoryla- 
tion alter the propagation speed of subsequently elicited spikes. Below, we compare these results with CaMKII responses in other preparations and relate propagation speed changes to afferent signal transmission by RGCs.

\section{Modulation of pT286 in optic nerve axons}

Because flickering illumination increases pT286 levels in RGC somata (Ogata et al., 2012), we were initially surprised to find that illumination and electrical stimulation decrease optic nerve pT286 levels (Figs. 4, 5). These decreases could result from dephosphorylation occurring alone or from dephosphorylation that outweighs concomitant phosphorylation. Our observations are consistent with the latter in that protein phosphatase inhibition counteracts the decrease of pT286 by electrical stimulation and increases pT286 staining intensity to levels exceeding that in unstimulated optic nerve (Fig. 5). The stimulation-induced decrease in pT286 that we found differs from earlier findings that depolarization and excitation increase CaMKII autophosphorylation (Molloy and Kennedy, 1991; Ocorr and Shulman, 1991). However, excitation has been found to reduce CaMKII autophosphorylation in hippocampus and parietal cortex (Yamagata and Obata, 1998), low and high levels of neuronal activity have been found to favor CaMKII phosphorylation and dephosphorylation, respectively (Gu and Yan, 2004), and NMDA receptor activation by low and high agonist concentrations has been found to increase and decrease CaMKII phosphorylation, respectively (Zhou et al., 2012). Moreover, the differential pT286 changes that we have found in RGC somata (Ogata et al., 2012) and optic nerve axons (Fig. 4) resemble the finding that elevated extracellular $\mathrm{KCl}$ depolarizes somata and axons of embryonic rat hippocampal neurons, elevates the intracellular free $\mathrm{Ca}^{2+}$ concentration in both compartments, and increases the pT286 immunostaining intensity in only the somata (Menegon et al., 2002). The parallel with our results is underscored by the increases in axonal pT286 produced by depolarizing the same neurons in the presence of okadaic acid (Menegon et al., 2002).

\section{Modulation of spike propagation by pT286}

The pT286 immunopositivity in unstimulated optic nerve axons (Fig. 3) resembles the basal levels of autophosphorylated CaMKII found in other unstimulated preparations (Molloy and Kennedy, 1991; Ocorr and Schulman, 1991) and raises the possibility that increases and decreases in pT286 can influence functional properties of resting and stimulated optic nerves. Consistent with this, we found that okadaic acid and fostriecin increased pT286 levels, accelerated spike propagation, and decreased interspike interval, whereas electrical stimulation decreased pT286 levels, slowed spike propagation, and increased interspike interval. Our finding that illumination lowers pT286 levels in optic nerve axons (Fig. 4) at an intensity and flicker frequency that translocates photoreceptor arrestin (Ogata et al., 2012) identifies a novel mechanism by which light adaptation can lower RGC spike frequency (Hayashida et al., 2009).

How do single spikes and changes in pT286 slow follower spike propagation? The simplest possibility is that they modulate one ion channel population that contributes to conduction velocity. Some studies have attributed propagation slowing to decreases of voltage-gated $\mathrm{Na}^{+}$conductance (Bliss and Rosenberg, 1979; De Col et al., 2008), low concentrations of tetrodotoxin reduce conduction velocity (Colquhoun and Ritchie, 1972), and depolarizations as brief as 2-3 ms inactivate RGC voltage-gated $\mathrm{Na}^{+}$current (Kim and Rieke, 2003; Hayashida and Ishida, 2004). However, the $\mathrm{Na}^{+}$current at adult rat optic nerve nodes of Ranvier appears to be carried by Nav 1.6 (Boiko et al., 2001) and this isoform is not significantly regulated by CaMKII (Chen et al., 2008; Aiba et al., 2010). A mixed cation current $\left(I_{\mathrm{h}}\right)$ is partially activated near resting potential in rat optic nerve (Eng et al., 1990), but RGC $I_{\mathrm{h}}$ is neither inactivated by depolarization (Lee and Ishida, 2007) nor known to be regulated by CaMKII. Last, a tetraethylammonium (TEA)-sensitive and 4-aminopyridine (4AP)-insensitive $\mathrm{K}^{+}$conductance reduces motoneuron conduction velocity after spikes (Baker et al., 1987), yet TEA has little (if any) effect on rat optic nerve spikes (Kocsis et al., 1986). By contrast, 4AP increases the time-to-peak of adult rat optic nerve CAPs (Foster et al., 1982; Devaux et al., 2002; Ogata, Partida, and Ishida, unpublished observations), 4AP-sensitive current can be inactivated by brief depolarizations (Debanne et al., 1997; Roeper et al., 1997; see also Geiger and Jonas, 2000), and $\mathrm{K}^{+}$currents through channels formed by Kv1.4 or Kv4.2 are inhibited by 4AP and increased by CaMKII (Roeper et al., 1997; Varga et al., 2004). Although Kv1.4 is absent in adult rat optic nerve (Rasband et al., 1999) and whether Kv4.2 is present is not yet known, voltageinduced inactivation of $\mathrm{Na}^{+}$current and 4AP-sensitive $\mathrm{K}^{+}$ current plus decreases in $4 \mathrm{AP}$-sensitive $\mathrm{K}^{+}$current by activityinduced decreases in pT286 could explain the propagation slowing that we observed. CaMKII inhibition and changes in pT286 levels might affect the response to single, paired, or multiple pulses by altering the $4 \mathrm{AP}$-sensitive $\mathrm{K}^{+}$conductance and thereby altering the time and space constants of optic nerve axons (Jack et al., 1975). On the other hand, inhibition of either CaMKII or PP2A would not be expected to alter $\mathrm{Na}^{+}$channel inactivation because the $\mathrm{Na}^{+}$channels are Nav1.6. Therefore, $\mathrm{Na}^{+}$channel inactivation could alter the response to paired pulses even if CaMKII is inhibited. 

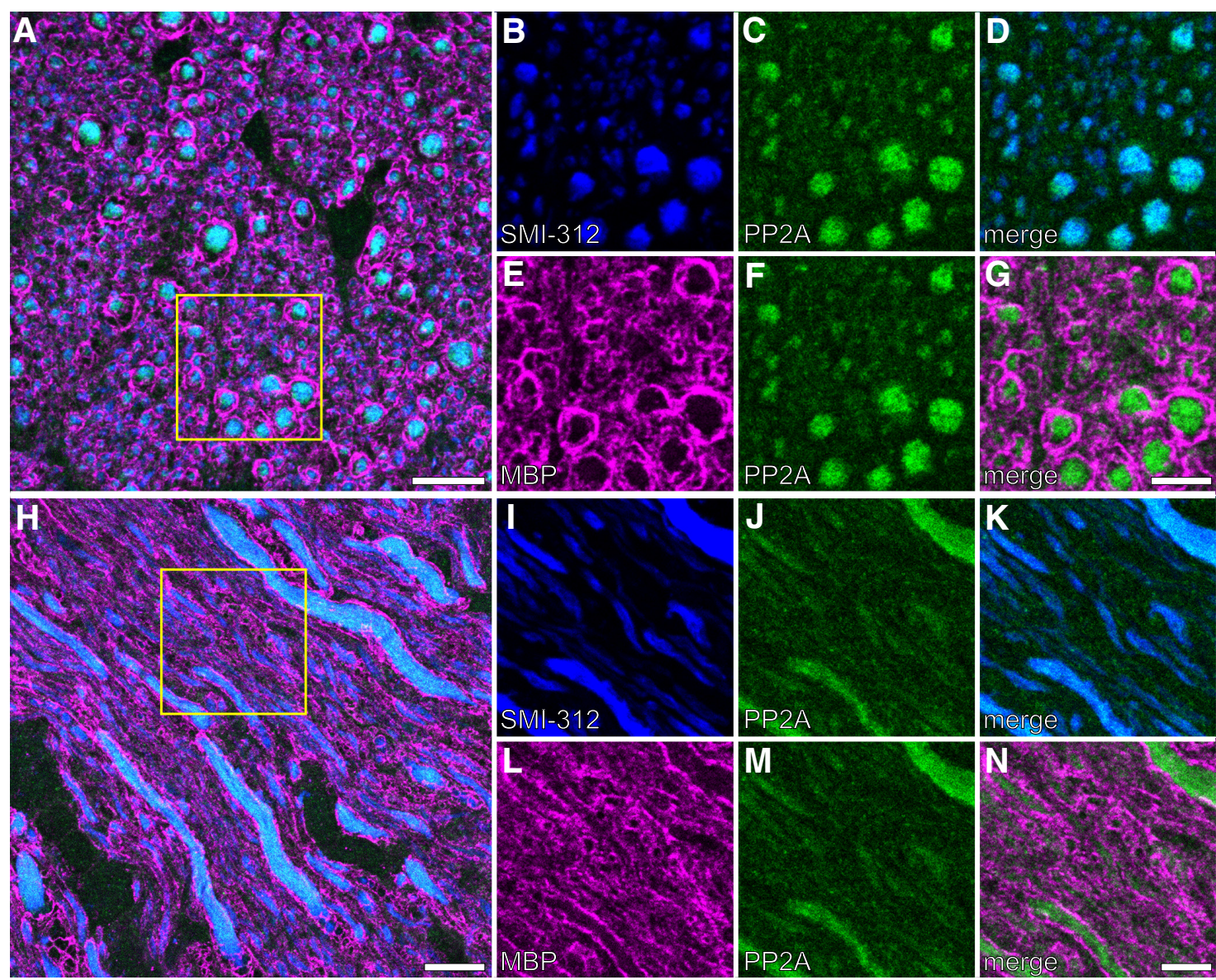

Figure 11. PP2A in optic nerve axons. Transverse $(\boldsymbol{A})$ and longitudinal $(\boldsymbol{H})$ sections triple-labeled for SMI-312 (blue), PP2A (green), and MBP (magenta). $\boldsymbol{B}-\boldsymbol{D}, \mathrm{SMl}-312(\boldsymbol{B})$ ), PP2A (C), and merge thereof (D) of the area within the yellow square in $\boldsymbol{A}$. SMI-312 and PP2A colocalization generates cyan. $\boldsymbol{E}-\boldsymbol{G}, \mathrm{MBP}(\boldsymbol{E}), \mathrm{PP} 2 \mathrm{~A}(\boldsymbol{F})$, and merge thereof $(\boldsymbol{G})$ of the same field as $\boldsymbol{D}$. Separation of magenta and green in $\mathbf{G}$ shows that PP2A localizes to axons and not to myelin. The axon diameters (e.g., in $\boldsymbol{A}$ and $\mathbf{G}$ ) range between small and large. $\boldsymbol{H}-\boldsymbol{N}$, Comparable information in cross-section, including colocalization (cyan in $\boldsymbol{K}$ ) of SMI-312 $(\boldsymbol{I})$ and PP2A $(\boldsymbol{J})$, separation $(\boldsymbol{N})$ of MBP $(\boldsymbol{L})$ and PP2A $(\boldsymbol{M})$, and wide range of axon diameters $(\boldsymbol{N})$. $\boldsymbol{I}-\boldsymbol{N}$, Field outlined by yellow square in $\boldsymbol{H}$. Scale bars: $\boldsymbol{A}, \boldsymbol{H}$ : $10 \mu \mathrm{m} ; \boldsymbol{G}, 3 \mu \mathrm{m}$ (applies to $\boldsymbol{B}-\boldsymbol{G}$ ); $\boldsymbol{N}, 3 \mu \mathrm{m}$ (applies to $\boldsymbol{I}-\boldsymbol{N}$ ).

\section{Spike frequencies in situ}

Our finding that single cardinal CAPs can slow the propagation of follower CAPs is consistent with recordings from optic tract (Bishop et al., 1953) and other preparations (Swadlow et al., 1980; Lüscher et al., 1994; George et al., 2007; Meeks and Mennerick, 2007).

These results suggest that, if spikes are elicited in RGCs intraretinally and recorded in the optic tract, then the spike intervals in the tract will be longer than the stimulus intervals in the retina. For example, we estimate that a stimulus frequency of 333 $\mathrm{Hz}$ at the retina (i.e., a pair of pulses separated by $3 \mathrm{~ms}$ ) will elicit spikes at an instantaneous frequency as low as $220 \mathrm{~Hz}$ at a distance of $20 \mathrm{~mm}$ from the eye (see Results). Moreover, we found that cardinal CAPs slowed follower CAP propagation by greater amounts as the stimulus intervals became shorter than $20 \mathrm{~ms}$ (Figs. $1 A, 12 C, D)$. This predicts that, at synapses where signal transmission probability increases with stimulus frequency, the probability will not increase at high stimulus frequencies as much as it does at low or moderate frequencies. This trend can be seen in plots of efficacy versus interspike intervals of RGCs (Usrey et al., 1998; Carandini et al., 2007) and of optic tract fibers (Singer et al., 1972). The spike slowing that we describe here might thus limit the spike frequencies that propagate along the optic nerve, chiasm, and tract and, in turn, that retinogeniculate synapses can transmit.
Although we have no means of assessing relative contributions, we suppose that activity-induced spike slowing will combine with LGN receptor desensitization to transmitter released by RGCs (Chen et al., 2002), presynaptic inhibition (Chen and Regehr, 2003), and postsynaptic summation (Carandini et al., 2007) to shape the frequency dependence of retinogeniculate signal transmission. At the same time, spike-induced increases in spike interval might not reduce signal transmission at synapses where single spikes transmit with very high efficacies, e.g., from RGCs to rat LGN P cells (Burke and Sefton, 1966), some mouse and cat LGN cells (Cleland and Lee, 1985; Blitz and Regehr, 2003), and optic tectum cells in frog (George et al., 1984) and salamander (Gollisch and Meister, 2008). Also, some rodent RGC populations may be organized to ensure signal transmission by other means, such as sampling of individual points in space by cells with overlapping dendritic fields (Peichl, 1989; Zhang et al., 2012), synapses from more than one RGC of a given type onto single LGN cells (Hammer et al., 2015; Weyand, 2016; Rompani et al., 2017), and homologous electrical coupling (Völgyi et al., 2013). By correlating spike firing in multiple RGCs, these properties might increase transmission efficacy, as found in LGN inputs to visual cortex (Alonso et al., 1996) and modeled for primate RGC spikes (Pillow et al., 2005).

On average, the time-to-peak of $\mathrm{P} 2$ and $\mathrm{P} 3$ increased more than that of $\mathrm{P} 1$ as stimulus interval decreased (Figs. $1 \mathrm{~A}, 12 \mathrm{D}$ ). 

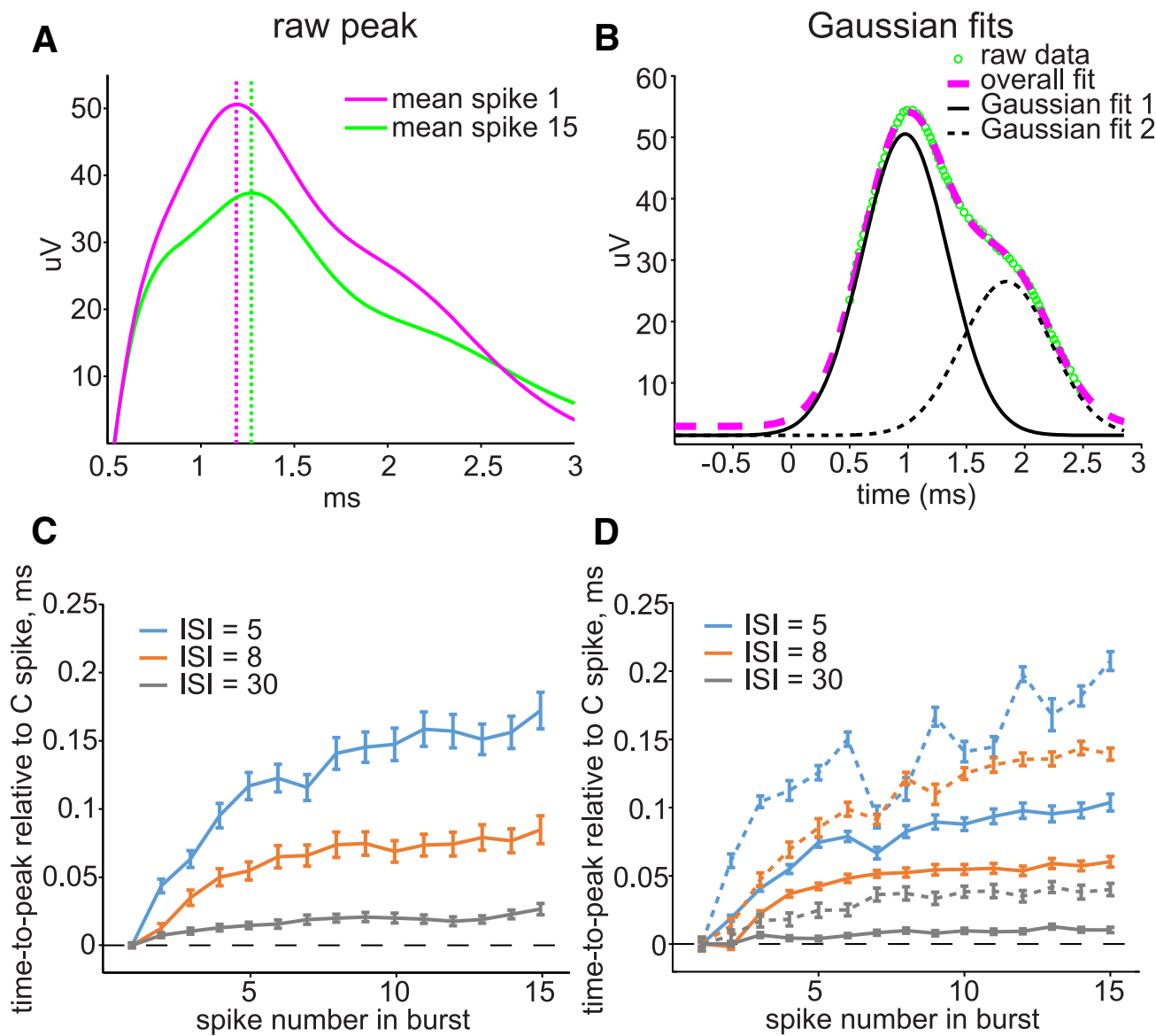

Figure 12. Spiking slows follower spike propagation in vivo. A, CAPs activated in optic chiasm and recorded in optic nerve (near optic foramen). Responses to the first (magenta) and fifteenth (green) pulse in a train of 15 stimulus pulses, all separated by $5 \mathrm{~ms}$. Traces are means from 76 repeats of the stimuli aligned to the beginning of the stimulus artifacts. Dashed vertical lines drawn through the maximum amplitude of the responses showing that the time-to-peak of the fifteenth CAP is longer than that of the first CAP. $B$, CAP (traced by green dots) elicited by a single pulse, displaying a larger peak at $t \approx 1 \mathrm{~ms}$ and a shoulder-like bulge at $t \approx 2 \mathrm{~ms}$. Plots of one Gaussian function peaking before (solid black line) and another peaking after (dashed black line) the large peak of the raw trace. The sum of these functions (dashed magenta line) follows the raw data trace on both the rising and falling phases. $C$, Effect of conditioning pulses on the time-to-peak of the large (maximum amplitude) peak recorded in three in vivo preparations. D, Effect of conditioning pulses on the time-to-peak of P1 (solid lines) and P2 (dashed lines) of CAPs in two preparations. C, D, Time-to-peak of the CAPs elicited by each of 15 pulses relative to that elicited by the first pulse. The values plotted are the means of the responses of each preparation to $40-50$ presentations of 15 pulses at each of $3 \mathrm{ISIs}(5,8$, and $30 \mathrm{~ms})$. Lines connect the means of the delays at each ISI. Error bars indicate \pm SEM.

This predicts that the maximum spike frequencies that can be reached by slowly conducting RGC axons are lower than those of rapidly conducting units (see Results) and this has been observed in vivo (Fukada et al., 1966; see also Swadlow, 1985; Perge et al., 2012). Would reducing spike frequency be advantageous? Possibly yes because it would tend to reduce vesicle depletion in single RGC axon terminals, permit more recovery from postsynaptic receptor desensitization at individual synapses (Chen et al., 2002), and reduce the energy required to maintain normal intracellular $\mathrm{Na}^{+}$and $\mathrm{Ca}^{2+}$ (Stys et al., 1992a; Attwell and Laughlin, 2001) concentrations. Our recordings showed that the fastest conduction velocities changed the least and the slowest conduction velocities changed the most. These might reflect an inverse relation between fiber size and increase in $\mathrm{Na}^{+}$concentration and/or lower amounts of CaMKII, less CaMKII autophosphorylation, or more avid pT286 dephosphorylation in smallerdiameter axons.

\section{References}

Aiba T, Hesketh GG, Liu T, Carlisle R, Villa-Abrille MC, O'Rourke B, Akar FG, Tomaselli GF $(2010) \mathrm{Na}^{+}$channel regulation by $\mathrm{Ca}^{2+} /$ calmodulin and $\mathrm{Ca}^{2+} /$ calmodulin-dependent protein kinase II in guinea-pig ventricular myocytes. Cardiovasc Res 85:454-463. CrossRef Medline
Alonso JM, Usrey WM, Reid RC (1996) Precisely correlated firing in cells of the lateral geniculate nucleus. Nature 383:815-819. CrossRef Medline

Attwell D, Laughlin SB (2001) An energy budget for signaling in the grey matter of the brain. J Cereb Blood Flow Metab 21:1133-1145. CrossRef Medline

Baden T, Berens P, Franke K, Román Rosón M, Bethge M, Euler T (2016) The functional diversity of retinal ganglion cells in the mouse. Nature 529:345-350. CrossRef Medline

Baker M, Bostock H, Grafe P, Martius P (1987) Function and distribution of three types of rectifying channel in rat spinal root myelinated axons. J Physiol 383:45-67. CrossRef Medline

Bernstein SL, Meister M, Zhuo J, Gullapalli RP (2016) Postnatal growth of the human optic nerve. Eye (Lond) 30:1378-1380. CrossRef Medline

Bialojan C, Takai A (1988) Inhibitory effect of a marine-sponge toxin, okadaic acid, on protein phosphatases. Biochem J 256:283-290. CrossRef Medline

Bishop PO, Jeremy D, Lance JW (1953) The optic nerve; properties of a central tract. J Physiol 121:415-432. CrossRef Medline

Bliss TV, Rosenberg ME (1979) Activity-dependent changes in conduction velocity in the olfactory nerve of the tortoise. Pflügers Arch 381:209-216. CrossRef Medline

Blitz DM, Regehr WG (2003) Retinogeniculate synaptic properties controlling spike number and timing in relay neurons. J Neurophysiol 90:24382450. CrossRef Medline

Boiko T, Rasband MN, Levinson SR, Caldwell JH, Mandel G, Trimmer JS, 
Matthews G (2001) Compact myelin dictates the differential targeting of two sodium channel isoforms in the same axon. Neuron 30:91-104. CrossRef Medline

Boycott BB, Wässle H (1974) The morphological types of ganglion cells of the domestic cat's retina. J Physiol 240:397-419. CrossRef Medline

Bronstein JM, Wasterlain CG, Bok D, Lasher R, Farber DB (1988) Localization of retinal calmodulin kinase. Exp Eye Res 47:391-402. CrossRef Medline

Brown AM, Westenbroek RE, Catterall WA, Ransom BR (2001) Axonal L-type $\mathrm{Ca}^{2+}$ channels and anoxic injury in rat CNS white matter. J Neurophysiol 85:900-911. CrossRef Medline

Brown JE, Rojas JA (1965) Rat retinal ganglion cells: receptive field organization and maintained activity. J Neurophysiol 28:1073-1090. CrossRef Medline

Burke W, Sefton AJ (1966) Discharge patterns of principal cells and interneurones in lateral geniculate nucleus of rat. J Physiol 187:201-212. CrossRef Medline

Calkins DJ, Sappington RM, Hendry SH (2005) Morphological identification of ganglion cells expressing the alpha subunit of type II calmodulindependent protein kinase in the macaque retina. J Comp Neurol 481: 194-209. CrossRef Medline

Carandini M, Horton JC, Sincich LC (2007) Thalamic filtering of retinal spike trains by postsynaptic summation. J Vis 7:20.1-11. CrossRef Medline

Chen C, Regehr WG (2003) Presynaptic modulation of the retinogeniculate synapse. J Neurosci 23:3130-3135. CrossRef Medline

Chen C, Blitz DM, Regehr WG (2002) Contributions of receptor desensitization and saturation to plasticity at the retinogeniculate synapse. Neuron 33:779-788. CrossRef Medline

Chen Y, Yu FH, Sharp EM, Beacham D, Scheuer T, Catterall WA (2008) Functional properties and differential neuromodulation of $\mathrm{Na}(\mathrm{v}) 1.6$ channels. Mol Cell Neurosci 38:607-615. CrossRef Medline

Cleland BG, Lee BB (1985) A comparison of visual responses of cat lateral geniculate nucleus neurones with those of ganglion cells afferent to them. J Physiol 369:249-268. CrossRef Medline

Colquhoun D, Ritchie JM (1972) The interaction at equilibrium between tetrodotoxin and mammalian non-myelinated nerve fibres. J Physiol 221: 533-553. CrossRef Medline

da Cruz e Silva EF, Fox CA, Ouimet CC, Gustafson E, Watson SJ, Greengard P (1995) Differential expression of protein phosphatase 1 isoforms in mammalian brain. J Neurosci 15:3375-3389. CrossRef Medline

Debanne D, Guérineau NC, Gähwiler BH, Thompson SM (1997) Actionpotential propagation gated by an axonal $\mathrm{I}(\mathrm{A})$-like $\mathrm{K}^{+}$conductance in hippocampus. Nature 389:286-289. CrossRef Medline

De Col R, Messlinger K, Carr RW (2008) Conduction velocity is regulated by sodium channel inactivation in unmyelinated axons innervating the rat cranial meninges. J Physiol 586:1089-1103. CrossRef Medline

De Juan J, Iñiguez C, Carreres J (1978) Number, diameter and distribution of the rat optic nerve fibers. Acta Anat 102:294-299. CrossRef Medline

Devaux J, Gola M, Jacquet G, Crest M (2002) Effects of $\mathrm{K}^{+}$channel blockers on developing rat myelinated CNS axons: identification of four types of $\mathrm{K}^{+}$channels. J Neurophysiol 87:1376-1385. CrossRef Medline

Dixon RG, Eng LF (1984) Myelin basic protein in the optic nerve of the developing albino rat: an immunoperoxidase study of paraffin embedded tissue. Neurochem Res 9:1387-1397. CrossRef Medline

Eng DL, Gordon TR, Kocsis JD, Waxman SG (1990) Current-clamp analysis of a time-dependent rectification in rat optic nerve. J Physiol 421:185202. CrossRef Medline

Evans RD, Weston DA, McLaughlin M, Brown AM (2010) A non-linear regression analysis method for quantitative resolution of the stimulusevoked compound action potential from rodent optic nerve. J Neurosci Methods 188:174-178. CrossRef Medline

Forrester J, Peters A (1967) Nerve fibres in optic nerve of rat. Nature 214: 245-247. CrossRef Medline

Foster RE, Connors BW, Waxman SG (1982) Rat optic nerve: electrophysiological, pharmacological and anatomical studies during development. Brain Res 255:371-386. Medline

Fukada Y, Motokawa K, Norton AC, Tasaki K (1966) Functional significance of conduction velocity in the transfer of flicker information in the optic nerve of the cat. J Neurophysiol 29:698-714. CrossRef Medline

Gao L, Blair LA, Marshall J (2006) CaMKII-independent effects of KN93 and its inactive analog KN92: reversible inhibition of L-type calcium channels. Biochem Biophys Res Commun 345:1606-1610. CrossRef Medline

Geiger JR, Jonas P (2000) Dynamic control of presynaptic $\mathrm{Ca}^{2+}$ inflow by fast-inactivating $\mathrm{K}^{+}$channels in hippocampal mossy fiber boutons. Neuron 28:927-939. CrossRef Medline

George A, Serra J, Navarro X, Bostock H (2007) Velocity recovery cycles of single C fibres innervating rat skin. J Physiol 578:213-232. CrossRef Medline

George SA, Mastronarde DN, Dubin MW (1984) Prior activity influences the velocity of impulses in frog and cat optic nerve fibers. Brain Res 304:121-126. CrossRef Medline

Gollisch T, Meister M (2008) Rapid neural coding in the retina with relative spike latencies. Science 319:1108-1111. CrossRef Medline

$\mathrm{Gu}$ Z, Yan Z (2004) Bidirectional regulation of $\mathrm{Ca}^{2+} /$ calmodulin-dependent protein kinase II activity by dopamine D4 receptors in prefrontal cortex. Mol Pharmacol 66:948-955. CrossRef Medline

Hammer S, Monavarfeshani A, Lemon T, Su J, Fox MA (2015) Multiple retinal axons converge onto relay cells in the adult mouse thalamus. Cell Rep 12:1575-1583. CrossRef Medline

Hartline K (1938) The response of single optic nerve fibers of the vertebrate eye to illumination of the retina. Am J Physiol 121:400-415.

Hayashida Y, Ishida AT (2004) Dopamine receptor activation can reduce voltage-gated $\mathrm{Na}^{+}$current by modulating both entry into and recovery from inactivation. J Neurophysiol 92:3134-3141. CrossRef Medline

Hayashida Y, Rodríguez CV, Ogata G, Partida GJ, Oi H, Stradleigh TW, Lee SC, Colado AF, Ishida AT (2009) Inhibition of adult rat retinal ganglion cells by D1-type dopamine receptor activation. J Neurosci 29:1500115016. CrossRef Medline

Heine WF, Passaglia CL (2011) Spatial receptive field properties of rat retinal ganglion cells. Vis Neurosci 28:403-417. CrossRef Medline

Hodgkin AL, Keynes RD (1956) Experiments on the injection of substances into squid giant axons by means of a microsyringe. J Physiol 131:592-616. CrossRef Medline

Ishida A, Shigeri Y, Taniguchi T, Kameshita I (2003) Protein phosphatases that regulate multifunctional $\mathrm{Ca}^{2+} /$ calmodulin-dependent protein $\mathrm{ki}-$ nases: from biochemistry to pharmacology. Pharmacol Ther 100:291305. CrossRef Medline

Jack JJB, Noble D, Tsien RW (1975) Electric current flow in excitable cells. Oxford, UK: Clarendon.

Khaliq ZM, Raman IM (2005) Axonal propagation of simple and complex spikes in cerebellar purkinje neurons. J Neurosci 25:454-463. CrossRef Medline

Kim KJ, Rieke F (2003) Slow $\mathrm{Na}^{+}$inactivation and variance adaptation in salamander retinal ganglion cells. J Neurosci 23:1506-1516. CrossRef Medline

Kocsis JD, Gordon TR, Waxman SG (1986) Mammalian optic nerve fibers display two pharmacologically distinct potassium channels. Brain Res 383:357-361. CrossRef Medline

Laabich A, Cooper NG (1999) Regulation of calcium/calmodulindependent protein kinase II in the adult rat retina is mediated by ionotropic glutamate receptors. Exp Eye Res 68:703-713. CrossRef Medline

Lang J, Reiter W (1985) Mass of the optic nerve, the optic chiasm and the optic tract of practical medical importance [Article in German]. Gegenbaurs Morphol Jahrb 131:777-795. Medline

Ledoux J, Chartier D, Leblanc N (1999) Inhibitors of calmodulindependent protein kinase are nonspecific blockers of voltage-dependent $\mathrm{K}^{+}$channels in vascular myocytes. J Pharmacol Exp Ther 290:1165-1174. Medline

Lee SC, Ishida AT (2007) $\mathrm{I}_{\mathrm{h}}$ without $\mathrm{K}_{\mathrm{ir}}$ in adult rat retinal ganglion cells. J Neurophysiol 97:3790-3799. CrossRef Medline

Lev-Ram V, Grinvald A (1987) Activity-dependent calcium transients in central nervous system myelinated axons revealed by the calcium indicator fura-2. Biophys J 52:571-576. CrossRef Medline

Lisman J, Schulman H, Cline H (2002) The molecular basis of CaMKII function in synaptic and behavioural memory. Nat Rev Neurosci 3:175190. CrossRef Medline

Liu LO, Li G, McCall MA, Cooper NG (2000) Photoreceptor regulated expression of $\mathrm{Ca}^{2+} /$ calmodulin-dependent protein kinase II in the mouse retina. Mol Brain Res 82:150-166. CrossRef Medline

Lund LM, McQuarrie IG (2001) Calcium/calmodulin-dependent protein kinase II alpha in optic axons moves with slow axonal transport and 
undergoes posttranslational modification. Biochem Biophys Res Commun 289:1157-1161. CrossRef Medline

Lüscher C, Streit J, Quadroni R, Lüscher HR (1994) Action potential propagation through embryonic dorsal root ganglion cells in culture. I. Influence of the cell morphology on propagation properties. J Neurophysiol 72:622-633. CrossRef Medline

Lüscher C, Lipp P, Lüscher HR, Niggli E (1996) Control of action potential propagation by intracellular $\mathrm{Ca}^{2+}$ in cultured rat dorsal root ganglion cells. J Physiol 490:319-324. CrossRef Medline

Mastronarde DN (1987) Two classes of single-input X-cells in cat lateral geniculate nucleus. II. Retinal inputs and the generation of receptive-field properties. J Neurophysiol 57:381-413. CrossRef Medline

Matheson DF (1970) Some quantitative aspects of myelination of the optic nerve in rat. Brain Res 24:257-269. CrossRef Medline

Matsuyama M, Nomori A, Nakakuni K, Shimono A, Fukushima M (2014) Secreted frizzled-related protein 1 (Sfrp1) regulates the progression of renal fibrosis in a mouse model of obstructive nephropathy. J Biol Chem 289:31526-31533. CrossRef Medline

Meeks JP, Mennerick S (2007) Action potential initiation and propagation in CA3 pyramidal axons. J Neurophysiol 97:3460-3472. CrossRef Medline

Meeks JP, Jiang X, Mennerick S (2005) Action potential fidelity during nor$\mathrm{mal}$ and epileptiform activity in paired soma-axon recordings from rat hippocampus. J Physiol 566:425-441. CrossRef Medline

Menegon A, Verderio C, Leoni C, Benfenati F, Czernik AJ, Greengard P, Matteoli M, Valtorta F (2002) Spatial and temporal regulation of $\mathrm{Ca}^{2+}$ / calmodulin-dependent protein kinase II activity in developing neurons. J Neurosci 22:7016-7026. CrossRef Medline

Molloy SS, Kennedy MB (1991) Autophosphorylation of type II $\mathrm{Ca}^{2+}$ / calmodulin-dependent protein kinase in cultures of postnatal rat hippocampal slices. Proc Natl Acad Sci U S A 88:4756-4760. CrossRef Medline

Monsivais P, Clark BA, Roth A, Häusser M (2005) Determinants of action potential propagation in cerebellar Purkinje cell axons. J Neurosci 25: 464-472. CrossRef Medline

Ochiishi T, Terashima T, Sugiura H, Yamauchi T (1994) Immunohistochemical localization of $\mathrm{Ca}^{2+} /$ calmodulin-dependent protein kinase II in the rat retina. Brain Res 634:257-265. CrossRef Medline

Ocorr KA, Schulman H (1991) Activation of multifunctional $\mathrm{Ca}^{2+}$ / calmodulin-dependent kinase in intact hippocampal slices. Neuron 6:907-914. CrossRef Medline

Ogata G, Stradleigh TW, Partida GJ, Ishida AT (2012) Dopamine and fullfield illumination activate D1 and D2-D5-type receptors in adult rat retinal ganglion cells. J Comp Neurol 520:4032-4049. CrossRef Medline

Peichl L (1989) Alpha and delta ganglion cells in the rat retina. J Comp Neurol 286:120-139. CrossRef Medline

Perge JA, Niven JE, Mugnaini E, Balasubramanian V, Sterling P (2012) Why do axons differ in caliber? J Neurosci 32:626-638. CrossRef Medline

Pillow JW, Paninski L, Uzzell VJ, Simoncelli EP, Chichilnisky EJ (2005) Prediction and decoding of retinal ganglion cell responses with a probabilistic spiking model. J Neurosci 25:11003-11013. CrossRef Medline

Raastad M, Shepherd GM (2003) Single-axon action potentials in the rat hippocampal cortex. J Physiol 548:745-752. CrossRef Medline

Rasband MN, Trimmer JS, Peles E, Levinson SR, Shrager P (1999) $\mathrm{K}^{+}$channel distribution and clustering in developing and hypomyelinated axons of the optic nerve. J Neurocytol 28:319-331. CrossRef Medline

Reese BE (1987) The distribution of axons according to diameter in the optic nerve and optic tract of the rat. Neuroscience 22:1015-1024. CrossRef Medline

Roeper J, Lorra C, Pongs O (1997) Frequency-dependent inactivation of mammalian A-type $\mathrm{K}^{+}$channel KV1.4 regulated by $\mathrm{Ca}^{2+} /$ calmodulindependent protein kinase. J Neurosci 17:3379-3391. CrossRef Medline

Rompani SB, Müllner FE, Wanner A, Zhang C, Roth CN, Yonehara K, Roska B (2017) Different modes of visual integration in the lateral geniculate nucleus revealed by single-cell-initiated transsynaptic tracing. Neuron 93:767-776.e6. CrossRef Medline

Sefton AJ, Swinburn M (1964) Electrical activity of lateral geniculate nucleus and optic tract of the rat. Vision Res 4:315-328. CrossRef Medline

Sekirnjak C, Hottowy P, Sher A, Dabrowski W, Litke AM, Chichilnisky EJ (2006) Electrical stimulation of mammalian retinal ganglion cells with multielectrode arrays. J Neurophysiol 95:3311-3327. CrossRef Medline
Sheng L, Leshchyns'ka I, Sytnyk V (2015) Neural cell adhesion molecule 2 promotes the formation of filopodia and neurite branching by inducing submembrane increases in $\mathrm{Ca}^{2+}$ levels. J Neurosci 35:1739-1752. CrossRef Medline

Sincich LC, Adams DL, Economides JR, Horton JC (2007) Transmission of spike trains at the retinogeniculate synapse. J Neurosci 27:2683-2692. CrossRef Medline

Singer W, Pöppel E, Creutzfeldt O (1972) Inhibitory interaction in the cat's lateral geniculate nucleus. Exp Brain Res 14:210-226. Medline

Stevens CF, Wang Y (1995) Facilitation and depression at single central synapses. Neuron 14:795-802. CrossRef Medline

Stys PK, Ransom BR, Waxman SG (1991) Compound action potential of nerve recorded by suction electrode: a theoretical and experimental analysis. Brain Res 546:18-32. CrossRef Medline

Stys PK, Waxman SG, Ransom BR (1992a) Ionic mechanisms of anoxic injury in mammalian CNS white matter: role of $\mathrm{Na}^{+}$channels and $\mathrm{Na}^{+}$$\mathrm{Ca}^{2+}$ exchanger. J Neurosci 12:430-439. CrossRef Medline

Stys PK, Waxman SG, Ransom BR (1992b) Effects of temperature on evoked electrical activity and anoxic injury in CNS white matter. J Cereb Blood Flow Metab 12:977-986. CrossRef Medline

Sugimoto T, Fukuda Y, Wakakuwa K (1984) Quantitative analysis of a cross-sectional area of the optic nerve: a comparison between albino and pigmented rats. Exp Brain Res 54:266-274. Medline

Sumi M, Kiuchi K, Ishikawa T, Ishii A, Hagiwara M, Nagatsu T, Hidaka H (1991) The newly synthesized selective $\mathrm{Ca}^{2+} /$ calmodulin dependent protein kinase II inhibitor KN-93 reduces dopamine contents in PC12h cells. Biochem Biophys Res Commun 181:968-975. CrossRef Medline

Sumitomo I, Ide K, Iwama K, Arikuni T (1969) Conduction velocity of optic nerve fibers innervating lateral geniculate body and superior colliculus in the rat. Exp Neurol 25:378-392. CrossRef Medline

Swadlow HA (1985) Physiological properties of individual cerebral axons studied in vivo for as long as one year. J Neurophysiol 54:1346-1362. CrossRef Medline

Swadlow HA, Kocsis JD, Waxman SG (1980) Modulation of impulse conduction along the axonal tree. Annu Rev Biophys Bioeng 9:143-179. CrossRef Medline

Tamagnini F, Scullion S, Brown JT, Randall AD (2014) Low concentrations of the solvent dimethyl sulphoxide alter intrinsic excitability properties of cortical and hippocampal pyramidal cells. PLoS One 9:e92557. CrossRef Medline

Tang X, Tzekov R, Passaglia CL (2016) Retinal cross talk in the mammalian visual system. J Neurophysiol 115:3018-3029. CrossRef Medline

Taylor JL, Burke D, Heywood J (1992) Physiological evidence for a slow $\mathrm{K}^{+}$ conductance in human cutaneous afferents. J Physiol 453:575-589. CrossRef Medline

Terashima T, Ochiishi T, Yamauchi T (1994) Immunocytochemical localization of calcium/calmodulin-dependent protein kinase II isoforms in the ganglion cells of the rat retina: immunofluorescence histochemistry combined with a fluorescent retrograde tracer. Brain Res 650:133-139. CrossRef Medline

Tsubokawa H, Offermanns S, Simon M, Kano M (2000) Calciumdependent persistent facilitation of spike backpropagation in the CA1 pyramidal neurons. J Neurosci 20:4878-4884. CrossRef Medline

Ulfig N, Nickel J, Bohl J (1998) Monoclonal antibodies SMI 311 and SMI 312 as tools to investigate the maturation of nerve cells and axonal patterns in human fetal brain. Cell Tissue Res 291:433-443. CrossRef Medline

Usrey WM, Reppas JB, Reid RC (1998) Paired-spike interactions and synaptic efficacy of retinal inputs to the thalamus. Nature 395:384-387. CrossRef Medline

Varga AW, Yuan LL, Anderson AE, Schrader LA, Wu GY, Gatchel JR, Johnston D, Sweatt JD (2004) Calcium-calmodulin-dependent kinase II modulates Kv4.2 channel expression and upregulates neuronal A-type potassium currents. J Neurosci 24:3643-3654. CrossRef Medline

Verbny Y, Zhang CL, Chiu SY (2002) Coupling of calcium homeostasis to axonal sodium in axons of mouse optic nerve. J Neurophysiol 88:802816. CrossRef Medline

Völgyi B, Pan F, Paul DL, Wang JT, Huberman AD, Bloomfield SA (2013) Gap junctions are essential for generating the correlated spike activity of neighboring retinal ganglion cells. PLoS One 8:e69426. CrossRef Medline 
Walsh AH, Cheng A, Honkanen RE (1997) Fostriecin, an antitumor antibiotic with inhibitory activity against serine/threonine protein phosphatases types 1 (PP1) and 2A (PP2A), is highly selective for PP2A. FEBS Lett 416:230-234. CrossRef Medline

Weitz AC, Behrend MR, Lee NS, Klein RL, Chiodo VA, Hauswirth WW, Humayun MS, Weiland JD, Chow RH (2013) Imaging the response of the retina to electrical stimulation with genetically encoded calcium indicators. J Neurophysiol 109:1979-1988. CrossRef Medline

Weyand TG (2007) Retinogeniculate transmission in wakefulness. J Neurophysiol 98:769-785. CrossRef Medline

Weyand TG (2016) The multifunctional lateral geniculate nucleus. Rev Neurosci 27:135-157. CrossRef Medline
Williams SR, Stuart GJ (1999) Mechanisms and consequences of action potential burst firing in rat neocortical pyramidal neurons. J Physiol 521: 467-482. CrossRef Medline

Yamagata Y, Obata K (1998) Dynamic regulation of the activated, autophosphorylated state of $\mathrm{Ca}^{2+} /$ calmodulin-dependent protein kinase II by acute neuronal excitation in vivo. J Neurochem 71:427-439. Medline

Zhang Y, Kim IJ, Sanes JR, Meister M (2012) The most numerous ganglion cell type of the mouse retina is a selective feature detector. Proc Natl Acad Sci U S A 109:E2391-E2398. CrossRef Medline

Zhou X, Zheng F, Moon C, Schlüter OM, Wang H (2012) Bi-directional regulation of CaMKII $\alpha$ phosphorylation at Thr286 by NMDA receptors in cultured cortical neurons. J Neurochem 122:295-307. CrossRef Medline 